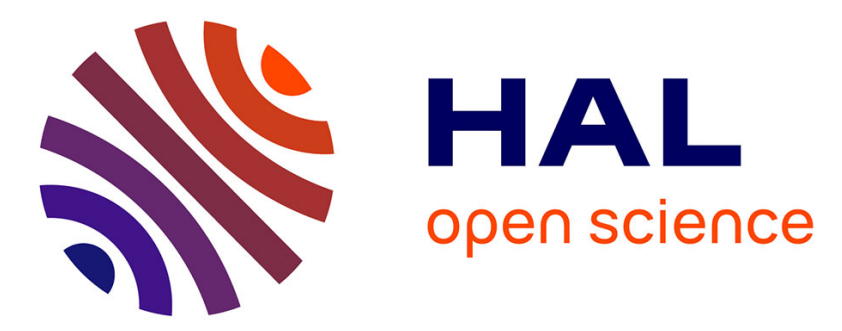

\title{
Petit poisson deviendra grand: les créatures aquatiques et leurs petits dans la littérature antique et médiévale
} Brigitte Gauvin

\section{To cite this version:}

Brigitte Gauvin. Petit poisson deviendra grand: les créatures aquatiques et leurs petits dans la littérature antique et médiévale. Anthropozoologica, 2021, 56 (17), pp.253-279. 10.5252/anthropozoologica2021v56a17 . hal-03525406

HAL Id: hal-03525406

https://hal-normandie-univ.archives-ouvertes.fr/hal-03525406

Submitted on 13 Jan 2022

HAL is a multi-disciplinary open access archive for the deposit and dissemination of scientific research documents, whether they are published or not. The documents may come from teaching and research institutions in France or abroad, or from public or private research centers.
L'archive ouverte pluridisciplinaire HAL, est destinée au dépôt et à la diffusion de documents scientifiques de niveau recherche, publiés ou non, émanant des établissements d'enseignement et de recherche français ou étrangers, des laboratoires publics ou privés. 


\section{anthropozoologica}

\section{$2021 \cdot 56 \cdot 17$}

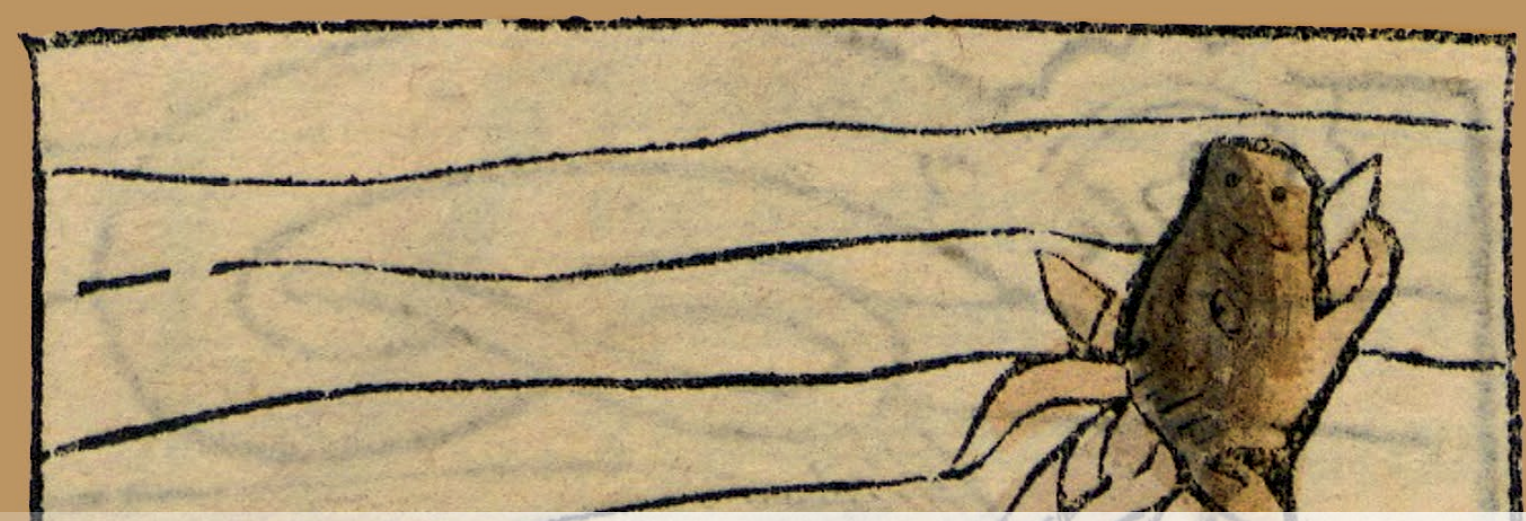

- Petit poisson deviendra grand... Les créatures aquatiques et leurs petits dans la littérature antique et médiévale

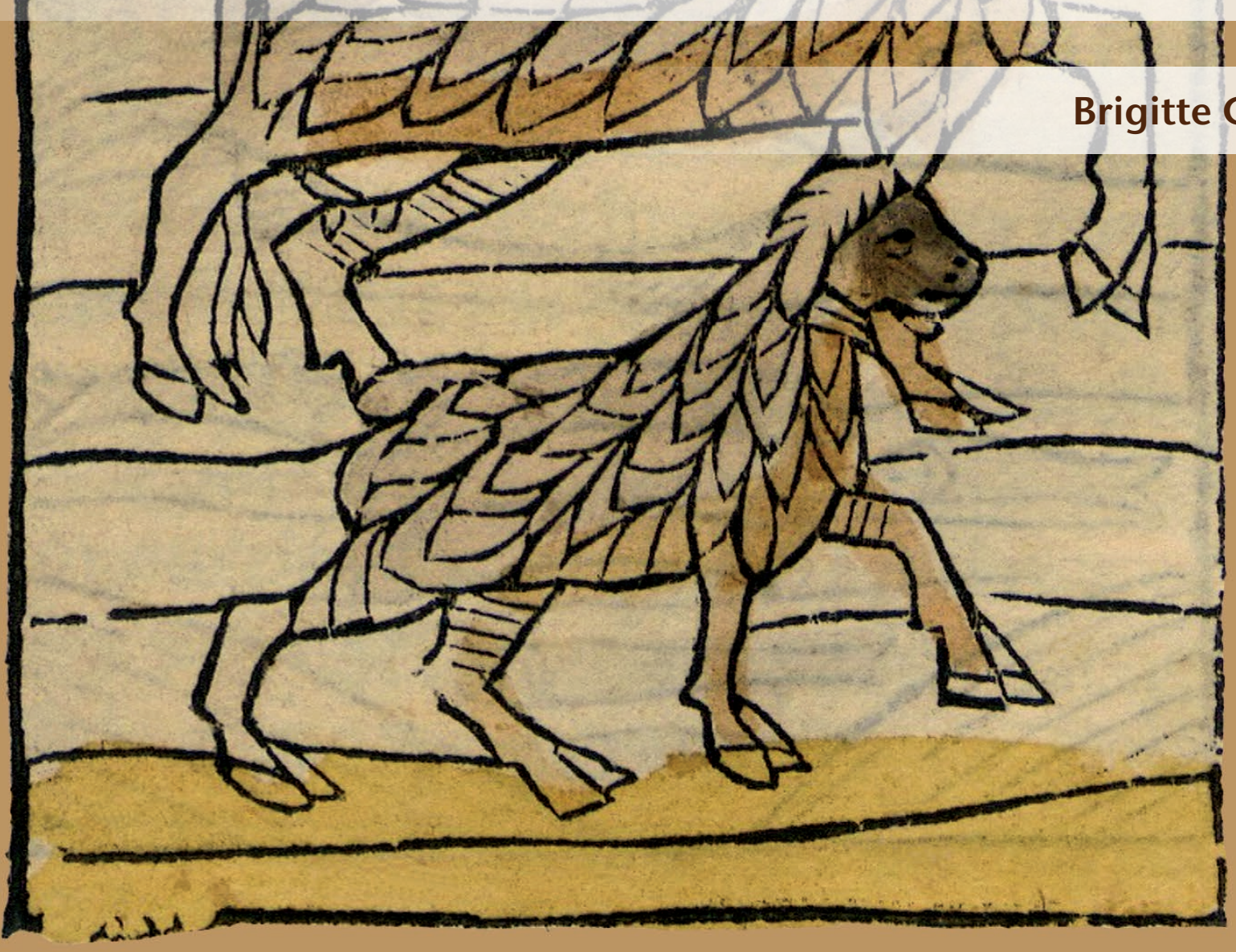


DiRECTEUR DE LA PUBLICATION / PUBLICATION DIRECTOR: Bruno David

Président du Muséum national d'Histoire naturelle

RÉDACTRICE EN CHEF / EDITOR-IN-CHIEF: Joséphine Lesur

RÉDACTRICE / EDITOR: Christine Lefèvre

RESPONSABLE dES ACTUALITÉS SCIENTIFIQUES / RESPONSIBLE FOR SCIENTIFIC NEWS: Rémi Berthon

AssisTANTE DE RÉDACTION / ASSISTANT EDITOR: Emmanuelle Rocklin (anthropo@mnhn.fr)

MISE EN PAGE / PAGE LAYOUT: Emmanuelle Rocklin, Inist-CNRS

COMITÉ SCIENTIFIQUE / SCIENTIFIC BOARD:

Louis Chaix (Muséum d'Histoire naturelle, Genève, Suisse)

Jean-Pierre Digard (CNRS, Ivry-sur-Seine, France)

Allowen Evin (Muséum national d'Histoire naturelle, Paris, France)

Bernard Faye (Cirad, Montpellier, France)

Carole Ferret (Laboratoire d'Anthropologie Sociale, Paris, France)

Giacomo Giacobini (Università di Torino, Turin, Italie)

Lionel Gourichon (Université de Nice, Nice, France)

Véronique Laroulandie (CNRS, Université de Bordeaux 1, France)

Stavros Lazaris (Orient \& Méditerranée, Collège de France - CNRS - Sorbonne Université, Paris, France)

Nicolas Lescureux (Centre dÉcologie fonctionnelle et évolutive, Montpellier, France)

Marco Masseti (University of Florence, Italy)

Georges Métailié (Muséum national d'Histoire naturelle, Paris, France)

Diego Moreno (Università di Genova, Gènes, Italie)

François Moutou (Boulogne-Billancourt, France)

Marcel Otte (Université de Liège, Liège, Belgique)

Joris Peters (Universität München, Munich, Allemagne)

François Poplin (Muséum national d'Histoire naturelle, Paris, France)

Jean Trinquier (École Normale Supérieure, Paris, France)

Baudouin Van Den Abeele (Université Catholique de Louvain, Louvain, Belgique)

Christophe Vendries (Université de Rennes 2, Rennes, France)

Denis Vialou (Muséum national d'Histoire naturelle, Paris, France)

Jean-Denis Vigne (Muséum national d'Histoire naturelle, Paris, France)

Arnaud Zucker (Université de Nice, Nice, France)

COUVERTURE / COVER:

Hortus sanitatis 4, 99, Vacca marina (Épernay, BM, Inc. 3017, 1491).

Anthropozoologica est indexé dans / Anthropozoologica is indexed in:

- Social Sciences Citation Index

- Arts \& Humanities Citation Index

- Current Contents - Social \& Behavioral Sciences

- Current Contents - Arts \& Humanities

- Zoological Record

- BIOSIS Previews

- Initial list de l'European Science Foundation (ESF)

- Norwegian Social Science Data Services (NSD)

- Research Bible

Anthropozoologica est distribué en version électronique par / Anthropozoologica is distributed electronically by:

- BioOne ${ }^{\circledR}$ (http://www.bioone.org)

Anthropozoologica est une revue en flux continu publiée par les Publications scientifiques du Muséum, Paris, avec le soutien du CNRS

Anthropozoologica is a fast track journal published by the Museum Science Press, Paris, with the support of the CNRS.

Les Publications scientifiques du Muséum publient aussi / The Museum Science Press also publish: Adansonia, Zoosystema, Geodiversitas,

European Journal of Taxonomy, Naturae, Cryptogamie sous-sections Algologie, Bryologie, Mycologie, Comptes Rendus Palevol.

Diffusion - Publications scientifiques Muséum national d'Histoire naturelle

CP $41-57$ rue Cuvier F-75231 Paris cedex 05 (France)

Tél. : 33 (0)1 40794805 / Fax: 33 (0)1 40793840

diff.pub@mnhn.fr / https://sciencepress.mnhn.fr

(c) Publications scientifiques du Muséum national d'Histoire naturelle, Paris, 2021

ISSN (imprimé / print): 0761-3032 / ISSN (électronique / electronic): 2107-08817 


\title{
Petit poisson deviendra grand... Les créatures aquatiques et leurs petits dans la littérature antique et médiévale
}

\author{
Brigitte GAUVIN \\ Centre Michel de Boüard - Centre de Recherches archéologiques et historiques \\ anciennes et médiévales (Craham), \\ Université de Caen Normandie, esplanade de la paix, CS 14032, F-14032 Caen cedex 5 (France) \\ brigitte.gauvin@unicaen.fr
}

Soumis le 28 août 2020 | Accepté le 25 novembre 2020 | Publié le 10 décembre 2021

MOTS CLÉS Animaux marins,

Moyen Âge,

encyclopédies

médiévales,

parentalité,

éthologie,

instinct animal,

Thomas de Cantimpré,

Liber de natura rerum.

KEY WORDS

Marine animals, Middle ages,

medieval encyclopedias,

parenthood, ethology,

animal instinct,

Thomas of Cantimpré,

Liber de natura rerum.
Gauvin B. 2021. - Petit poisson deviendra grand... Les créatures aquatiques et leurs petits dans la littérature antique et médiévale. Anthropozoologica 56 (17): 253-279. https://doi.org/10.5252/anthropozoologica2021v56a17. http:// anthropozoologica.com/56/17

\section{RÉSUMÉ}

Parmi les animaux, ceux qui occupent les mers et les rivières sont les plus difficiles à observer et, de ce fait, les plus mal connus; ils nourrissent ainsi un grand nombre de fantasmes. Cependant, les savants de l'antiquité ont prêté à certains d'entre eux un comportement parental, qui peut varier selon les espèces et apparaître ainsi comme un élément de caractérisation; et les encyclopédistes médiévaux ont pris soin de transmettre ces informations et même, semble-t-il, d'accentuer ces traits. En s'appuyant sur une étude précise des sources antiques et des encyclopédies médiévales ainsi que sur l'iconographie qui, parfois, les accompagne, et en tentant de contextualiser le discours encyclopédique, on tentera de comprendre les différentes origines de ces comportements prêtés aux animaux marins.

\section{ABSTRACT}

Little fish will grow big... Aquatic creatures and their young in ancient and medieval littérature.

Among the animals, those occupying the seas and rivers are the most difficult to observe, and consequently they are not as well known as birds or terrestrial animals and therefore generate fantasies. However, scholars in Antiquity have attributed to a few of them parenting behavior which differs from one species to another and can be considered as a specific feature, and medieval encyclopedists carefully collected and transmitted these informations, and even accentuated the parental behaviors. Relying on a precise study of ancient and medieval sources and on the illustrations that can sometimes be present in some manuscripts, and contextualizing encyclopedic writings, we will try to explain where the fishes' parental behavior described in medieval encyclopedias come from. 


\section{INTRODUCTION}

On a longtemps cru, dans la perspective des études initiées par Ariès (1975), que le Moyen Âge n'aimait pas ses enfants. En dépit de leur présence nombreuse, puisque les femmes mettent au monde plusieurs enfants, plus de cinq en règle générale, le taux élevé de mortalité infantile aurait retenu les parents de s'attacher trop fortement à des êtres dont l'existence avait toutes les chances d'être brève: au Moyen Âge, toutes périodes confondues, un enfant sur deux seulement arrive en âge de procréer ; trois enfants sur dix meurent avant l'âge d'un an et presque autant avant la puberté. Le plus grand nombre de décès se produit avant trois mois (Alexandre-Bidon \& Lett 1997: 61-64). Cependant, si la période médiévale a inévitablement eu son lot d'enfants malheureux, orphelins, enfants des rues ou enfants placés précocement et abusés, des études plus récentes, notamment celles de Didier Lett (2000), ont montré que, dans le cadre de la famille, les enfants semblent avoir été protégés et très aimés. Or, si la famille nucléaire existe dès la fin de l'Antiquité tardive, c'est au XII ${ }^{\mathrm{e}}$ siècle et au XIII ${ }^{\mathrm{e}}$ qu' elle émerge nettement comme forme principale de la structure familiale, comme le montre l'archéologie en s'appuyant notamment sur la taille des demeures (Alexandre-Bidon \& Lett 1997: 97, 98). Dans ce cadre plus restreint, et donc plus propice aux relations, les liens parents-enfants se resserrent.

Cette nouvelle proximité est sensible dans deux domaines, l'éducatif et l'affectif. L'éducation consiste avant tout, pour tous les enfants, à être élevés dans la foi chrétienne, et c'est là un domaine dévolu pour l'essentiel à la mère, même si le père y participe par l'exemple et la pratique quotidienne. À cette instruction s'ajoute, concernant les garçons, l'apprentissage d'un métier pour les enfants de milieu modeste, souvent réalisé aux côtés du père, celui des armes pour les autres et, selon les cas, un peu d'instruction scolaire à des degrés très divers (Alexandre-Bidon \& Lett 1997: 73-96). Les filles reçoivent une éducation en rapport avec les devoirs liés à leur sexe, doublée le plus souvent, dans la noblesse, d'une éducation intellectuelle et artistique (Alexandre-Bidon \& Lett 1997: 75, 76, 83, 84). L'apprentissage commence très tôt par des tâches simples et avec des outils adaptés qui familiarisent l'enfant avec son métier ou son activité future, et les parents sont alors les principaux éducateurs des enfants, exception faite du domaine scolaire où des maîtres les remplacent. Mais le souci éducatif est véritablement présent. Parlant du XII ${ }^{\text {e }}$ siècle, qu'il oppose à l'Antiquité, Lett (2000: 189) écrit: «Dans l'ensemble de l'Europe, les pères ont su se transformer en pédagogues et rédiger des traités d'éducation pour leurs enfants». On trouve ainsi le Liber legum moralium du Milanais Bellino Bissolo, la Doctrina pueril du Catalan Raymond Lulle, le Winsbeck d'un Bavarois anonyme; au XIVe siècle fut rédigé le Livre pour l'enseignement de ses filles du chevalier de la Tour Landry ou, au Xve siècle, les Enseignements paternels destinés par Ghillebert de Lannoy à son fils adolescent. Comme mère et père ont chacun leurs responsabilités et leurs domaines propres dans l'éducation, les contes et fabliaux regorgent d'exemples montrant les conséquences d'une mauvaise éducation ou d'une éducation incomplète, par exemple menée par un seul parent.
Les préoccupations éducatives des parents au Moyen Âge ne constituent cependant pas la totalité de leurs relations avec leurs enfants; à côté du souci d'une bonne éducation, tant à la maison qu'à l'école, les sources nous permettent de constater que la famille est un lieu de protection et d'amour, tant maternel que paternel. L'infanticide, rarissime, est lourdement condamné s'il advient; il est le crime condamnable par excellence et la marque de la barbarie, le meurtre des nouveauxnés étant associé à Hérode et aux peuples barbares, tandis que le nouveau-né renvoie, dans son innocence, à l'image du Christ (Alexandre-Bidon \& Lett 1997: 34). L'abandon, plus rare dans la période prospère du Moyen Âge classique que lors des crises du début et de la fin de la période, ne semble avoir été pratiqué que sous la contrainte économique la plus criante, et rarement sans douleur, comme en témoignent les menus objets qui accompagnent souvent les nouveauxnés abandonnés, à commencer par l'attestation de baptême (Alexandre-Bidon \& Lett 1997: 36-39; Lett 2000: 205, 206). De très nombreux documents montrent que les pères comme les mères ressentent une forte affection pour leur progéniture et qu'ils sont soumis au désespoir lorsque les choses tournent mal. Si l'amour des mères, littéralement viscéral, est le plus souvent dépeint comme un amour intense, parfois excessif, nombre de textes montrent aussi les pères pleurant devant la maladie ou la mort de leur enfant, «se précipitant chez le médecin, courant de sanctuaire en sanctuaire» pour reprendre les mots de D. Alexandre-Bidon et D. Lett, qui fournissent nombre de témoignages émouvants de chagrin parental (Alexandre-Bidon \& Lett 1997: 74; 99-101; 106-108). Les pères, contrairement à une idée reçue, semblent aussi très présents dans les actions de maternage de la petite enfance, que les circonstances l'imposent ou non (Alexandre-Bidon \& Lett 1997: 112-116). Loin d'être inexistants, les sentiments des parents pour les enfants au Moyen Âge sont donc si forts qu'ils servent d'outil de comparaison lorsqu'on veut évoquer d'autres affections de grande intensité. Il est d'ailleurs significatif que l'affection portée aux petits enfants les accompagne jusque dans la mort. Souvent enterrés dans une partie spécifique des cimetières, plus proche des habitations, comme pour maintenir un lien, les enfants bénéficient de tombes soignées, voire de cercueils de plomb. Il n'est pas rare de trouver dans les tombes enfantines des vêtements, des jouets et de petits objets témoignant de l'amour des parents (Alexandre-Bidon \& Lett 1997: 52-60).

Or tous ces éléments, affection qui dure au-delà de la mort, éducation partagée entre parents, protection vigilante de la petite enfance, sont mentionnées par les encyclopédistes médiévaux dans leur description de la "nature» des animaux. Les encyclopédies médiévales naissent à la fin du XII ${ }^{e}$ siècle et connaissent leur apogée au XIII ${ }^{e}$, dans un contexte d'accroissement du savoir consécutif à la diffusion d'ouvrages traduits du grec et de l'arabe et au développement des universités. Soucieuses de rendre compte de la totalité des connaissances de leur temps tout en les rendant accessibles par le biais d'ouvrages de synthèse, elles se donnent des objectifs d'exhaustivité, de brièveté et de fidélité aux sources à partir desquelles elles se sont constituées, tout en se dotant d'outils 
méthodologiques, comme les index, l'ordre alphabétique et les marqueurs de citations, qui les rendent faciles à utiliser. Les encyclopédistes s'appuient sur les sources antiques profanes, latines (Pline, Solin), grecques (Aristote), chrétiennes (Isidore de Séville, Ambroise), sur les bestiaires et, notamment pour la médecine, sur les sources arabes; on trouve aussi des sources plus récentes comme Jacques de Vitry. Mais il existe aussi de forts liens d'interdépendance entre les encyclopédies elles-mêmes car les encyclopédistes, qui appartiennent presque tous à l'ordre dominicain, tout en donnant à leur œuvre une structure propre qui reflète la vision qu'a chaque auteur de l'organisation de la création, utilisent tous des citations déjà sélectionnées et répertoriées par leurs prédécesseurs, qu'ils complètent avec d'autres sources, de sorte que les encyclopédies, à partir d'un socle commun, croissent en nombre de livres et de rubriques au fil du temps. Ainsi, si le De naturis rerum d'Alexandre Nequam (c. 1200) ne consacre que deux livres aux choses naturelles, avec un classement approximatif par éléments et de courts chapitres, Barthélemy l'Anglais publie en 1247 un Liber de proprietatibus rerum en 19 livres dont chacun correspond à une catégorie étudiée et se divise en très nombreux chapitres. Thomas de Cantimpré quant à lui choisit d'orienter son œuvre plus spécifiquement sur les res naturales. Il publie un Liber de natura rerum d'abord en 19 livres, en 1240, puis en 20 livres, vers 1244, après un remaniement qui lui permet d'intégrer les connaissances apportées par les livres d'Aristote sur les animaux, tout juste traduits. Albert le Grand suit avec plus encore de radicalité cette démarche de spécialisation dans le De animalibus qu'il achève vers 1270 : il s'agit d'un commentaire de l'œuvre zoologique d'Aristote en 19 livres suivi de sept livres très inspirés de l'œuvre de Thomas de Cantimpré, dont chacun correspond à une catégorie de Pline (animaux qui marchent, volent, nagent, rampent...) et déploie, dans l'ordre alphabétique, entre 100 et 200 chapitres. Les ouvrages et les informations circulent sans cesse entre les trois dominicains et c'est encore un autre dominicain, Vincent de Beauvais, qui tente une synthèse universelle de toutes les connaissances de son temps, le Speculum maius, achevé en 1263, divisé en trois specula, Speculum historiale, Speculum naturale et Speculum doctrinale. Le Speculum naturale, ouvrage d'une taille considérable, qui compte les autres encyclopédies parmi ses sources, fut à son tour, avec d'autres œuvres comme les Pandectes, le De animalibus d'Albert le Grand et le Gart der Gesundheit de Jakob Meydenbach, la source d'une des dernières encyclopédies du Moyen Âge, l'Hortus sanitatis imprimé en 1491 à Mayence. Ce corpus encyclopédique fournit sur les animaux un certain nombre d'informations issues de sources variables, qui subissent parfois des modifications d'une encyclopédie à l'autre, mais qui constitue globalement un socle commun de savoir zoologique. La description de l'animal et l'évocation de quelques traits de comportement figurent dans une partie du chapitre appelée natura; elle peut s'accompagner d'interprétations allégoriques ou de conseils pratiques concernant la diététique ou la médecine.

Or, de manière assez surprenante, à l'intérieur des encyclopédies médiévales, les relations entre adultes et petits parfois mentionnées dans la natura des animaux sont très peu pré- sentes dans l'évocation des quadrupèdes, à propos desquels les mentions de liens parentaux sont la plupart du temps limitées à l'allaitement, et uniquement sous un angle physiologique. On apprend par ailleurs que l'ourse met au monde des masses informes de chair et qu'elle les lèche pendant quelques jours pour leur donner forme, mais aucune notation affective n'est présente, de même que pour les lions dont les petits naissent morts et qui sont ressuscités le troisième jour par les rugissements (ou le souffle) paternels. La guenon est montrée comme une mère qui préfère un de ses petits à l'autre, comportement qui entraîne paradoxalement la perte du favori. Exceptions notables, le tigre et la belette mettent leur rapidité à profit pour sauver leurs petits si ceux-ci sont pourchassés par les hommes, la belette étant de surcroît capable, si ses petits meurent, de se mettre en quête d'une plante capable de les ressusciter. L'évocation des liens parents-enfants est donc réduite.

L'éducation, pas toujours tendre, les soins et l'affection sont en revanche souvent mentionnés à propos des oiseaux (l'aigle, le canard, le corbeau, la corneille, le pélican, figure christique, etc.), et font même parfois l'objet d'illustrations comme dans les chapitres consacrés au linachos ou au pélican (Thomas de Cantimpré, Liber de natura rerum. Médiathèque S. Veil, Valenciennes, Ms 320, f. 102 v, 105 r.) ; et ce phénomène se retrouve, à un degré moindre, mais de manière plus étonnante, dans les chapitres consacrés aux animaux marins. Ceux-ci, difficiles à observer et mal connus, ne font qu'une entrée progressive dans la littérature consacrée aux animaux. Ils sont presque absents du Physiologus où, par ailleurs, la nature des animaux est surtout présentée pour servir de base à l'allégorie qui suit, ce qui lui confère un caractère bien artificiel; on ne trouve ainsi que la serre (ch. 4, un animal mythique), l'huître et la perle (ch. 23), le cète (ou aspidochelon, ch. 30), l'hydre (milvus, qui est aussi un serpent, ch. 38) et la grenouille (ch. 44). S'ils sont plus présents dans les bestiaires, notamment par le biais des sources que sont Isidore de Séville, Solin et surtout Ambroise, les rubriques individuelles évoquent rarement, en parlant de chaque espèce, les traits de nature autres que ceux qui concernent la nourriture et la prédation; il est cependant très intéressant de noter que dans les bestiaires de la deuxième famille, à propos des animaux marins, le chapitre le plus développé est un chapitre de généralités consacré à la reproduction et, plus particulièrement, à la manière dont certains animaux marins prennent soin de leur progéniture (Clark 2006: 208-214). On y retrouve presque textuellement les indications présentes chez Ambroise à propos de l'affection extraordinaire de la baleine envers ses petits mais aussi, à plusieurs reprises, toujours venant d'Ambroise, une personnification des flots qui se comportent envers les œufs des poissons comme une mère de substitution qui les berce et les caresse. Le fait que ce discours très empreint d'affectivité qui fait d'un animal monstrueux, la baleine, et d'un élément inanimé, la mer, des modèles à suivre, ait été introduit dans un bestiaire rédigé au XIII ${ }^{\mathrm{e}}$ siècle, alors qu'il ne figurait pas dans les bestiaires de la première famille, semble annoncer ce qu'on va trouver dans les encyclopédies. Dans celles-ci, les poissons et animaux aquatiques, relégués, dans l'ordre des livres, derrière les quadrupèdes et les oiseaux et juste avant 
les petits animaux (vermes), sont souvent les parents pauvres. Peu et mal connus, difficiles à différencier, ils sont le plus souvent brièvement décrits et de manière approximative. Il est cependant notable que lorsque les sources mentionnent les liens entre parents et petits, les encyclopédistes retiennent systématiquement ces informations et les développent. Dès l'Antiquité, Aristote et Pline avaient remarqué et commenté l'attachement des cétacés à leurs petits, chez le dauphin bien sûr, qui bénéficie chez Pline de longs développements où il est souvent doté d'un comportement et de sentiments proches de ceux de l'homme, mais aussi chez la baleine. Aristote, de surcroît, toujours suivi par Pline, avait aussi noté l'attention parentale des phoques et, par la suite, des animaux plus petits ont eux aussi été observés sous cet angle, comme le poulpe pour les céphalopodes, ou le silure et l'épinoche pour les poissons proprement dits.

Cependant, comme l'a montré B. Ribémont (1995: 383399), la notion d'instinct animal n'a pas encore émergé dans les encyclopédies médiévales. La vision de l'animal est alors la résultante de diverses traditions, symbolique et "littéraire» d'une part, scientifique de l'autre. S'appuyant sur des sources où domine l'observation, notamment Aristote, les savants pensent que l'animal ne possède pas de raison mais agit en fonction de deux critères fondamentaux, le plaisir et la préservation, de lui-même et de l'espèce. Ce sont les "potentialités naturelles» et la «sagacité», pour reprendre les termes aristotéliciens, qui sont à l'œuvre. Par ailleurs, ce qui intéresse au premier chef les encyclopédistes dans les écrits antiques, dans la lignée moralisante des bestiaires et dans la perspective de compilation des savoirs qui est la leur, toujours cependant dans le but d'illustrer la grandeur de la puissance divine, c'est la liste d'exemples comportementaux qu'ils y trouvent. Leur réflexion sur le comportement animal ne peut donc s'inscrire que dans ce cadre, même s'il est indéniable qu'une réflexion s'amorce, à petit bruit, comme nous le verrons, et que des savants comme Barthélemy l'Anglais ou Albert le Grand commencent à poser des questions, ou émettre des hypothèses qui ouvrent un espace à la notion d'intelligence animale.

L'objectif de cet article est de montrer, d'une part, quelles informations sont transmises par les encyclopédies à propos des relations entre les poissons et leurs petits et, de l'autre, si celles-ci se trouvent modifiées par rapport aux sources antiques et dans quelle mesure. Peut-on considérer que la vision de l'enfant développée au Moyen Âge a eu une influence sur le discours savant consacré aux animaux? Nous nous appuierons bien évidemment sur l'étude des textes et de leurs sources mais aussi, dans la mesure du possible, sur l'iconographie, puisque certains manuscrits du Liber de natura rerum de Thomas de Cantimpré sont illustrés (Van den Abeele 2008). En organisant notre étude selon les différents types de comportement mettant en relation des animaux aquatiques et leurs petits, nous étudierons successivement comment certains sont décrits comme des parents nourriciers, d'autres comme des parents éducateurs, d'autres encore comme des parents défenseurs et, pour finir, comment certains animaux aquatiques sont dépeints comme de mauvais parents, source de danger pour leur progéniture.
ABRÉVIATIONS
AM, $D A$
AS, DNR
Albert le Grand, De animalibus;
Arist., $H A$
BA, DPR
$H S$
MS, $H A$
Arnold de Saxe, De floribus rerum naturalium;
Aristote, Histoire des animaux;
Barthélemy l'Anglais, De proprietatibus rerum;
Hortus sanitatis;
à partir de l'arabe, $c$. 1220)
TC, DNR Thomas de Cantimpré, Liber de natura rerum;
VB, SN Vincent de Beauvais, Speculum naturale.

\section{LES PARENTS NOURRICIERS}

Chez les cétacés et les pinnipèdes, tous mammifères, l'allaitement est une des caractéristiques systématiquement mises en valeur lorsque sont mentionnés les liens entre adultes et jeunes. Deux éléments peuvent expliquer l'attention qu'ont portée les anciens à ce phénomène: d'une part, contrairement aux quadrupèdes et aux oiseaux, les poissons ne se soucient pas de nourrir leurs petits, qui sont immédiatement autonomes à cet égard : l'attitude des cétacés et pinnipèdes est donc unique dans le règne aquatique, ce qui suffit à attirer l'attention des savants; de l'autre, le rapprochement avec l'homme et les quadrupèdes entraîné par la pratique de l'allaitement chez les cétacés semble avoir fasciné, les mamelles et le lait étant dans l'imaginaire collectif réservés aux créatures terrestres ou éventuellement à des créatures hybrides comme la sirène (Leclercq-Marx 2002: 55-67). Le Moyen Âge vit dans l'idée que les différents mondes, terrestre, céleste et marin, se correspondent. Pour reprendre les termes de J. Leclercq-Marx (2006: 259-271), il ne s'agit "sans doute pas d'un concept structuré, mais une idée sousjacente à la théologie et à la cosmographie de l'époque, au confluent de plusieurs cultures ", qui explique notamment que grand nombre d'animaux marins sont dotés d'un nom terrestre (lièvre de mer, veau de mer, chien de mer) ou céleste (corbeau de mer, hirondelle de mer, grive de mer). Il semble que le lien ait été particulièrement fort entre terre et mer si l'on en croit par exemple Gervais de Tilbury, selon lequel "il n'y a pas d'être vivant habitant sur notre terre dont on ne puisse observer l'image ressemblante chez les poissons de la mer d'Angleterre " (Leclercq-Marx 2006: 259). Malgré cette croyance, pourtant, les univers sont clairement distingués par leur population et leurs mœurs: les mammifères (quadrupèdes ou bipèdes) peuplent la terre, marchent, font des petits vivants et les allaitent; les oiseaux peuplent le ciel, volent, pondent des œufs et nourrissent à la becquée des oisillons incapables de pourvoir à leur propre entretien; enfin les poissons vivent dans l'eau, nagent et pondent des œufs qu'ils abandonnent ensuite à un sort incertain. Dans ce contexte, trouver dans les flots des animaux pourvus de mamelles et allaitant leurs petits provoquait donc un effet de miroir surprenant entre terre et mer, et cette incongruité ne pouvait qu'interroger et étonner les savants de l'Antiquité et du Moyen Âge. Dès Aristote, plusieurs passages témoignent de cette particularité, tant à propos des cétacés que des phoques: 
«En effet le dauphin est vivipare, et c'est pour cela qu'il a deux mamelles [...] Cependant il n'a pas de mamelons apparents mais deux espèces d'orifices, un de chaque côté, d'où le lait s'écoule. Et les petits tètent en nageant derrière la mère: le fait a été certifié par des gens qui l'ont vu. » (Arist., HA II, 13, 504 b 21-26 [Louis 1964: 55])

"Tous les animaux qui ont du lait l'ont dans les mamelles [...] par exemple les cétacés comme le dauphin, le marsouin et la baleine. » (Arist., HA III, 20, 521 b 24 [Louis 1964: 106])

"[...] le dauphin et le marsouin ont du lait et allaitent leurs petits. [...] Les petits suivent la mère pendant longtemps et celle-ci leur est très attachée.» (Arist., HA VI, 12, 566 b 21-23 [Louis 1968: 87])

"[Le phoque] met au monde des petits vivants, et expulse le chorion et le reste comme une brebis. Il fait un petit, deux, maximum trois. Il possède deux mamelles et ses petits le tètent comme les petits des quadrupèdes. » Arist., $H A$ VI, 12, 566b 28 [Louis 1968: 87])

Les remarques d'Aristote seront reprises par Pline:

"Quae pilo vestiuntur, animal pariunt, ut pristis, ballaena, vitulus. Hic parit in terra, pecudum more secundas partus reddit. [...] parit nonnumquam geminis plures, educat mammis fetum. Non ante duodecimum diem deducit in mare, ex eo subinde adsuefaciens." (Plin., nat. 9, 41-42 [De Saint-Denis 1955: 51])

(Ceux qui sont vêtus de poil sont vivipares comme la scie, la baleine, le veau marin. Celui-ci met bas à terre, et, à la façon des quadrupèdes, il expulse un arrière-faix. [...] parfois la femelle met bas plus de deux petits; elle les nourrit de ses mamelles; elle attend le douzième jour pour les emmener à la mer; ensuite elle le fait souvent pour les y habituer.)

Dans un passage ne concernant que le phoque, Michel Scot, dans sa traduction de 1220, traduit ainsi Aristote, de manière assez fidèle malgré l'intermédiaire arabe:

"Et generat animal per se, et quando exit fetus, exibit cum eo secundina et similiter animalia alia sicut oves et ipse parit [unum] aut duo aut tres, et habet mamillas." (Arist., $H A$ VI, 12, 566b 28 - 567a 12 [MS, HA])

(Et il met bas un petit, et, quand celui-ci vient au monde, la mère expulse aussi un arrière-faix; et, comme d'autres animaux ainsi que les brebis, il a un, deux ou trois petits, et il a des mamelles.)

Mais un peu plus tôt dans le texte, la similitude entre cétacés et pinnipèdes, à la fois parce qu'ils sont vivipares, mammiferres et parce qu'ils se montrent attentifs envers leurs petits, pousse Michel Scot à élargir au phoque une remarque faite ailleurs par Aristote sur le dauphin. Dans le passage suivant,

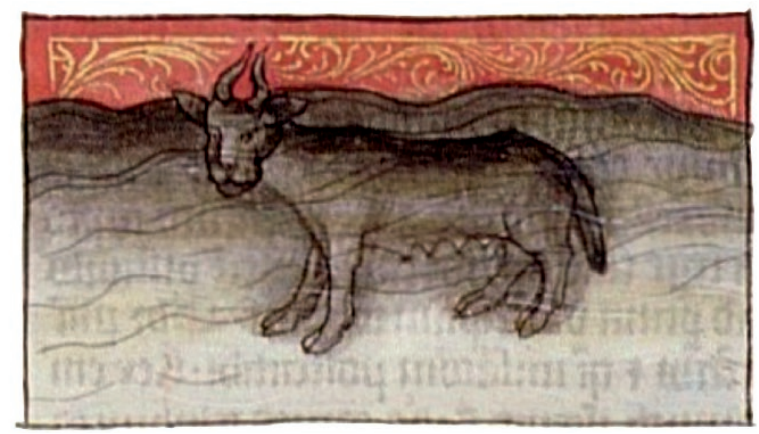

FIG. 1. - Thomas de Cantimpré, De natura rerum 7, 22, (F)Elchus ([Codex granatensis]. De natura rerum, De avibus nobilibus, Tacuinum sanitatis. Granada, Biblioteca Universitaria y Provincial, C-67, f. 57v).

originellement consacré au dauphin, Scot ajoute de son propre chef et kokane (et le phoque):

"Et delfin et kokane habent lac et lactant fetus et cubant eos, dum sunt parvi.» (Arist., HA VI, 12, 566 b 16 [MS, HA])

(Le dauphin et le phoque ont du lait et allaitent leurs petits et les maternent tant qu'ils sont petits.)

Reprenant Michel Scot, Arnold de Saxe écrit à son tour :

\section{"[...] et delfin et corave habent lac et lactant fetus et cibant eos dum sint parvi [...]»}

([...] le dauphin et le phoque ont du lait, allaitent leurs petits et les nourrissent tant qu'ils sont petits [...]).

L'ajout de Michel Scot est cependant plus lourd de conséquences chez Thomas de Cantimpré. Celui-ci, en effet, étend l'assimilation phoque/cétacés aux remarques qui suivent en croyant qu'elles concernent aussi les deux animaux, alors qu'elles ne concernaient que le phoque, et il les utilise dans le chapitre qu'il consacre à la vacca marina: ainsi le chapitre Vacca de Thomas de Cantimpré est composé pour moitié d'éléments concernant le phoque, et pour moitié d'éléments concernant le dauphin.

Chez Thomas de Cantimpré, les remarques issues de Pline et d'Aristote concernant l'allaitement chez les phoques se trouvent reprises dans trois chapitres: Felchus, Helchus, Vacca marina, avec toujours les mêmes indications sur la viviparité, l'existence d'un placenta et la présence de mamelles permettant l'allaitement. Ainsi, tout naturellement, certains illustrateurs se sont appuyés sur cet élément spécifique: l'illustration du chapitre elchus dans le manuscrit de Thomas de Cantimpré conservé à Grenade (Fig. 1) fait de cet animal un ruminant marin, et on voit clairement une longue rangée de mamelles (évoquant plus la truie que la vache) sous le ventre de l'animal. Dans le très beau manuscrit de Valenciennes, la vacca marina conjugue une tête de vache, un corps de poisson et un pis dont les trayons possèdent une extrémité soulignée par une pointe de blanc, détail témoignant de l'attention portée par l'illustrateur à cette caractéristique extraordinaire dans un contexte aquatique (on retrouve d'ailleurs la même mise en valeur par 


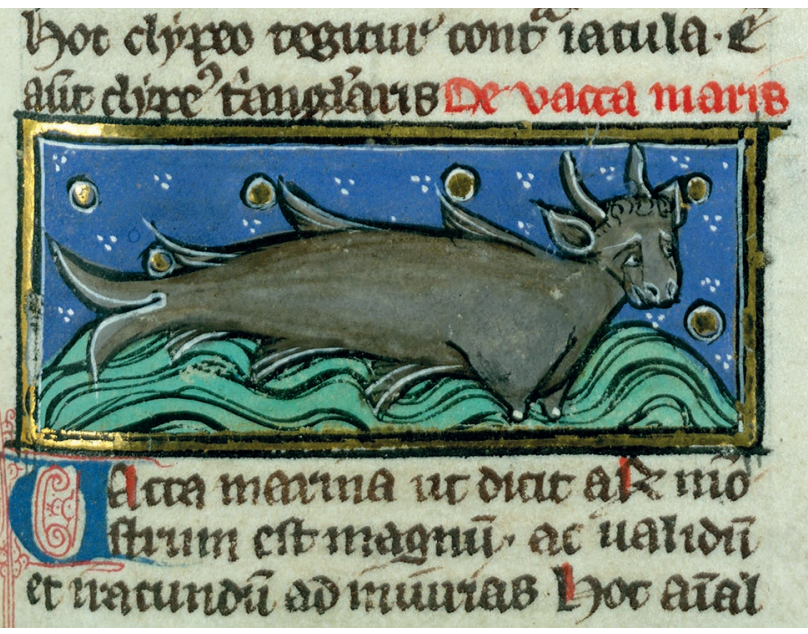

FIG. 2. - Thomas de Cantimpré, Liber de natura rerum 7, 55, Vacca marina (Valenciennes, Médiathèque S. Veil, Ms 320, f. 120r).

une touche de blanc pour le tygnus, malencontreusement doté de mamelles suite à une contamination avec une notice concernant le singe (Fig. 2).

\section{LES «POISSONS» ÉDUCATEURS : CÉTACÉS, PHOQUES ET TORTUES}

L'allaitement nécessite une proximité constante entre la mère et le petit et de nombreux encyclopédistes indiquent comment les petits des mammifères marins suivent leur mère pendant une longue durée, souvent imprécise. Mais au-delà de la nécessité, les textes insistent sur l'amour entre les parents et les petits qui constitue le fondement de cet accompagnement et cette proximité physique semble dépasser les besoins de l'allaitement pour devenir un acte éducatif à part entière.

Commençons par les dauphins, qui apparaissent comme des spécialistes de la prise en charge de la petite enfance. Dès l'antiquité, Aristote lui-même signale le fait:

«[...] le dauphin et le marsouin ont du lait et allaitent leurs petits [...] Les petits suivent la mère pendant longtemps et celle-ci leur est très attachée.» (Arist., HA VI, 12, 566 b 21-23 [Louis 1968: 87])

Il est repris par nombre de savants:

"[...] pariunt catulos decimo mense aestivo tempore, interim et binos. Nutriunt uberibus, sicut ballaena atque etiam gestant fetus infantia infirmos; quin et adultos diu comitantur magna erga partum caritate." (Plin., nat. 9, 21 [De Saint-Denis 1955: 44])

([les dauphins] mettent bas au bout de dix mois, en été, parfois deux petits à la fois; ils les allaitent comme la baleine et même les portent lorsqu'ils ont la faiblesse du premier âge; même lorsqu' ils ont grandi ils les accompagnent encore longtemps, pleins de tendresse pour leur progéniture.)
"[...] delphini fetum alunt [...], inualidos aliquantisper prosequuntur.» (Solin, Coll. 12, 3)

([...] les dauphins nourrissent leurs petits [...], ils les accompagnent longtemps quand ils sont faibles.)

Au Moyen Âge, les encyclopédistes orientent visiblement le texte dans une direction plus affective, ce qui est visible par les ajouts qu'ils opèrent. Concernant la durée de l'accompagnement maternel chez la baleine, Albert le Grand, après avoir repris le diu de Pline, donne une précision dont la source est inconnue mais qu'il semble tirer de l'exemple humain : jusqu'à l'âge de trois ou quatre ans, durée qui marque chez l'homme la fin de la petite enfance ${ }^{1}$ :

"Concipit autem balaena unum et nutrit eum et diu sequitur matrem forte usque ad aetatem trium vel quatuor annorum.» (AM, DA 24, 23, Cetus)

(La baleine fait un petit et le nourrit, celui-ci suit longtemps sa mère, jusqu'à l'âge de trois ou quatre ans.)

Thomas de Cantimpré quant à lui, parlant des dauphins, n'hésite pas à faire durer cet accompagnement «jusqu'à l'âge adulte", en cas de fragilité particulière; cette attitude se justifie par l'adverbe au superlatif qui est un ajout de son cru: les dauphins aiment selon lui leurs petits «très tendrement» (tenerrime). Certes, le texte d'Aristote avait déjà cette nuance d'affectivité

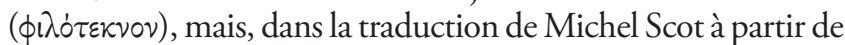
laquelle Thomas de Cantimpré a travaillé, on lit simplement: "quoniam hoc animal diligit suos pullos magno tempore» (puisque cet animal chérit ses petits pendant une longue période). On peut donc supposer que Thomas, ému par l'attitude des dauphins, a traduit son sentiment par l'ajout de tenerrime:

"Diligunt enim eos tenerrime et longo tempore ducunt post se, et sub aqua sequuntur matrem. At ubi ad robur etatis fetus pervenerint, nisi validi sint, eos etiam matres persequuntur." (TC, DNR 6, 16)

(En effet, ils aiment leurs petits très tendrement, et ils les emmènent longtemps derrière eux, et les petits suivent leur mère sous l'eau. Mais quand ceux-ci parviennent à l'âge adulte, les mères les accompagnent s'ils ne sont pas solides.)

On franchit un degré supplémentaire dans l'éducation avec le cas des phoques, puisque la manière dont ceux-ci accompagnent leurs petits prend en outre un aspect didactique. Aristote écrit en effet:

"Quand ses petits ont une douzaine de jours, il les conduit à la mer plusieurs fois par jour, pour les habituer progressivement.» (Arist., HA VI, 12, 566b 28sq [Louis 1968: 87])

1. Chez la baleine, la durée de la lactation est très variable selon les espèces, et s'étend sur un peu moins d'un an, sauf chez le cachalot, qui nourrit son petit pendant au moins trois ans. Le petit reste auprès de sa mère pendant ce temps. Chez le dauphin, la lactation dure jusqu'à 18 mois environ et le petit reste aux côtés de la mère jusqu'à l'âge de six ou sept ans. 
Tous ses suiveurs reprendront soigneusement cette anecdote, de Pline:

"[...] parit nonnumquam geminis plures, educat mammis fetum. Non ante duodecimum diem deducit in mare [...]" (Plin., nat. 9, 41 [De Saint-Denis 1955])

([...] parfois la femelle met bas plus de deux petits; elle les nourrit de ses mamelles. Elle attend le douzième jour pour les emmener à la mer [...])

\section{à Albert le Grand:}

"Hoc animal parit in terra et lactando mammis nutrit catulos, nec ante XII dies ducit eos ad mare." (AM, DA)

(Cet animal met bas sur la terre ferme, nourrit ses petits du lait de ses mamelles et ne les mène pas à l'eau avant qu'ils aient douze jours.)

en passant par Thomas de Cantimpré:

"Hic parit in terra pecudum more. Parit nunquam geminis plures. Educat fetus et mammis lactat nec ante duodecim dies deducit in mare." (TC, DNR 6, 22, De Helco)

(Il met ses petits au monde sur la terre ferme, à la manière du bétail. Il n'a jamais plus de deux petits. Il veille sur ses petits, les allaite et ne les mène pas à la mer avant qu'ils aient douze jours).

Si le phoque est donc montré ici comme un véritable éducateur, sachant attendre la maturité nécessaire et fondant sa pédagogie, selon Aristote, sur la répétition de l'exercice, il convient cependant de s'interroger sur le sens du verbe educare. En latin classique, educare, concernant les animaux, signifie «élever, nourrir, avoir soin de, veiller sur la croissance de». Un passage de Cicéron, dans le De natura deorum, illustre ce sens:

"Quid dicam quantus amor bestiarum sit in educandis custodiendis que is quae procreaverunt, usque ad eum finem dum possint se ipsa defendere. etsi pisces, ut aiunt, ova cum genuerunt relinquunt, facile enim illa aqua et sustinentur et fetum fundunt; testudines autem et crocodilos dicunt, cum in terra partum ediderint, obruere ova, deinde discedere: ita et nascuntur et educantur ipsa per sese." (Cicéron, De natura deorum 2, 129)

(À quoi bon rappeler comme est grand l'amour que les animaux portent à leurs petits dans la manière dont ils élèvent et protègent ceux qu'ils ont mis au monde, jusqu'à ce que ceux-ci puissent se défendre par eux-mêmes - même si, à ce qu'on dit, les poissons laissent leurs œufs une fois qu'ils les ont pondus : en effet ces œufs sont soutenus par l'eau et donnent naissance à des petits. On dit que les tortues et les crocodiles, après avoir pondu à terre, recouvrent leurs œufs et les abandonnent. Ainsi les petits naissent et s'élèvent par eux-mêmes.)

En associant educandis et custodiendis, Cicéron montre bien les deux actions complémentaires faites par les animaux: nourrir et protéger. Ce sens est confirmé par la fin du passage consacré aux poissons: comme les parents abandonnent les œufs après la ponte, les petits, écrit Cicéron, educantur ipsa per sese (s'élèvent par eux-mêmes) : le verbe prend alors un emploi moyen-passif pour signifier «se nourrir» ou «veiller sur soi». C'est sans doute le sens qu'il possède dans la phrase de Pline. Lorsque Thomas de Cantimpré transforme la phrase de celui-ci educat mammis fetum (il nourrit ses petits à la mamelle) en educat fetus et mammis lactat (il élève ses petits et les allaite), cela semble montrer qu'il a besoin de distinguer les deux actions, réunies dans le raccourci de Pline: educare pour l'action de protection ou de veille, lactare pour l'action de nourrir.

Dans le chapitre Vacca marina, animal composé d'éléments appartenant au dauphin et d'autres appartenant au phoque, comme nous l'avons vu ci-dessus, Vincent de Beauvais signale un accompagnement purement affectif: la vacca "chérit tendrement son petit et l'emmène avec elle partout où elle va» (Fetum tenere diligit et secum ducit ubicumque vadit). Mais la phrase se situe parmi d'autres caractéristiques empruntées en fait au dauphin. On retrouve donc ici l'attachement sentimental des cétacés pour leurs petits signalé supra.

Notons avant d'en terminer avec les mammifères marins que les illustrateurs ont été sensibles à cet aspect nourricier et accompagnateur en ce qui concerne les phoques (figurés comme des veaux et vaches de mer), comme le montrent par exemple les illustrations de l'Hortus sanitatis (Figs 3; 4), la proximité des petits avec les adultes étant nettement montrée: soit on voit l'animal, à l'arrière-plan, veiller sur les deux petits en train de s'initier au milieu aquatique, soit on le voit marcher au milieu des flots, flanqué de son petit représenté comme une miniature de lui-même.

Pour finir, et de manière un peu surprenante, les tortues d'eau méritent d'être citées dans cette partie, qu'il s'agisse de tortues d'eau douce ou d'eau de mer, parce qu'elles se caractérisent, dans les textes anciens et médiévaux, par l'attention portée à leurs œufs, voire à leurs petits. À l'origine, on trouve un texte d'Aristote qui va servir de matrice à tous ses successeurs, sans grand changement en ce qui concerne le texte lui-même:

"Pour ce qui est de la tortue ( $\dot{\eta} \chi \varepsilon \lambda \omega \nu \eta)$, elle pond des oufs à la coquille dure et qui sont de deux couleurs comme ceux des oiseaux; quand elle les a pondus, elle les enfouit dans la terre dont elle foule la surface. Cela fait, elle vient fréquemment se poser dessus pour les couver. Et les œufs éclosent l'année suivante.

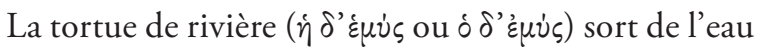
pour pondre; elle creuse un trou qui a la forme d'un tonneau, y pond ses œufs et les abandonne. Après les avoir laissés ainsi moins de trente jours, elle les déterre, les fait éclore rapidement et emmène aussitôt ses petits dans l'eau.

Les tortues de mer $(\theta \alpha \lambda \dot{\alpha} \tau \tau \iota \alpha \iota) \chi \varepsilon \lambda \omega \dot{\omega} \nu \alpha)$ pondent elles aussi à terre des œufs qui ressemblent à ceux des oiseaux domestiques; elles les enfouissent et les couvent la nuit. Elles pondent un grand nombre d'œufs; elles en pondent, 


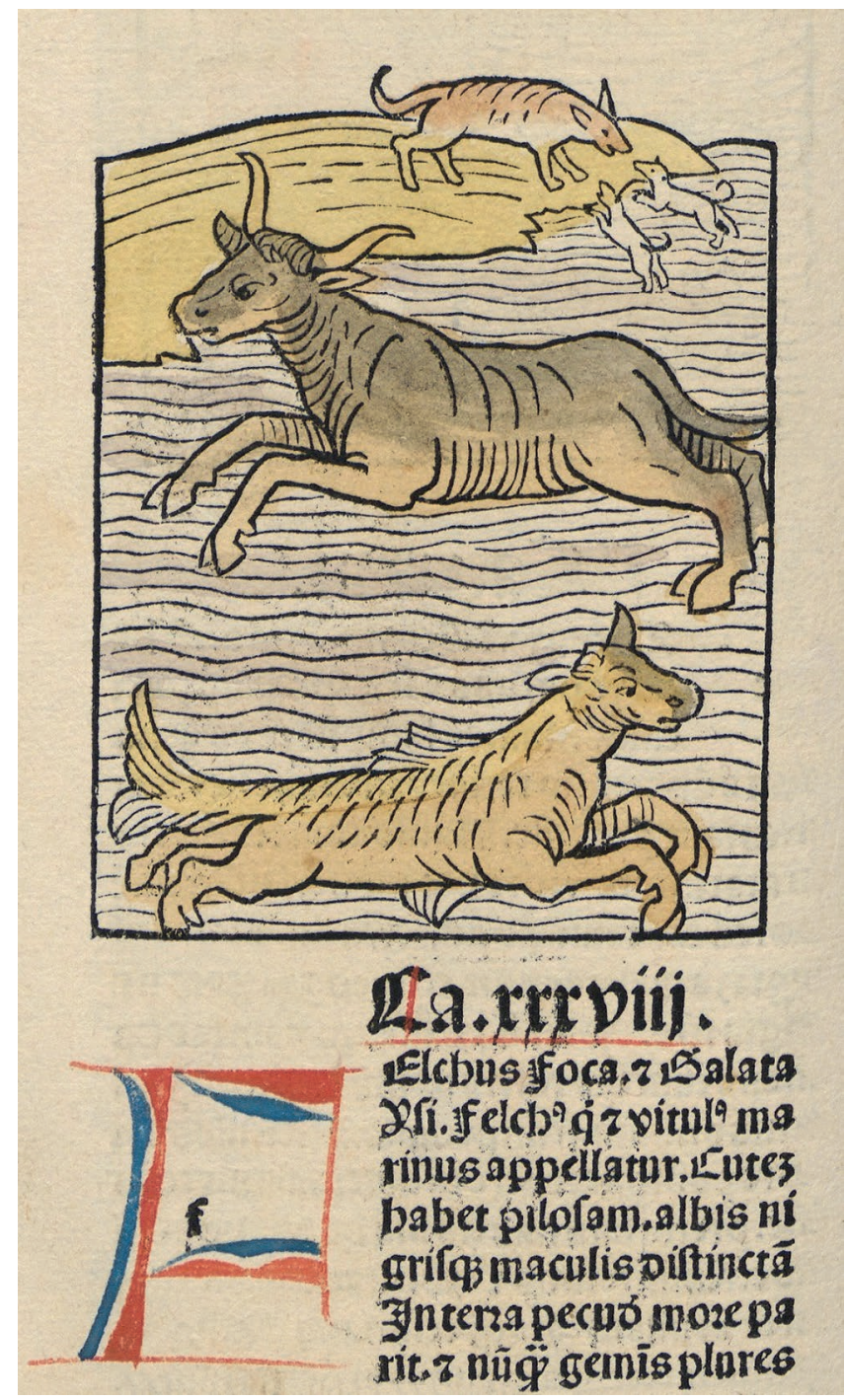

FIG. 3. - Hortus sanitatis 4, 38, Felchus, foca, galata (Épernay, BM, Inc. 3017, 1491): le phoque ou veau marin est à l'arrière-plan, veillant sur ses deux petits qu'il a menés à l'eau.

en effet, jusqu'à cent. ${ }^{2}{ }^{\prime}$ (Arist., $H A \mathrm{~V}, 33,558$ a 7-11 [Louis 1968: 59, 60])

Chez les encyclopédistes médiévaux, les informations fournies par Aristote vont se retrouver dans les notices concernant deux animaux. Les informations concernant la tortue de terre vont figurer dans les chapitres testudo des encyclopédies, bien que ce terme désigne une tortue de mer, tandis que celles qui concernent la tortue de rivière, suite à une mélecture de Pline ou de ses sources, vont se trouver attribuées à l'animal imaginaire baptisé mus marinus, littéralement «le rat de

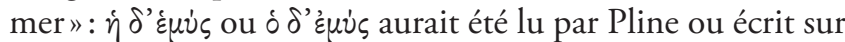
le texte qu'il consultait $\dot{\eta} \delta \dot{\varepsilon} \mu \tilde{v} \varsigma$ ou $\delta \delta \varepsilon \dot{~} \mu \tilde{v} \varsigma$, le rat ou la souris.

2. Les informations fournies par Aristote ne sont que partiellement exactes: la tortue pond bien la nuit, et le nombre d'œufs est bien celui qu'il indique. En revanche, la durée de maturation des œufs est plutôt de six à huit semaines et surtout il n'y a pas de couvaison. Une fois les œufs pondus, la tortue repart et ne se soucie plus de sa future progéniture.

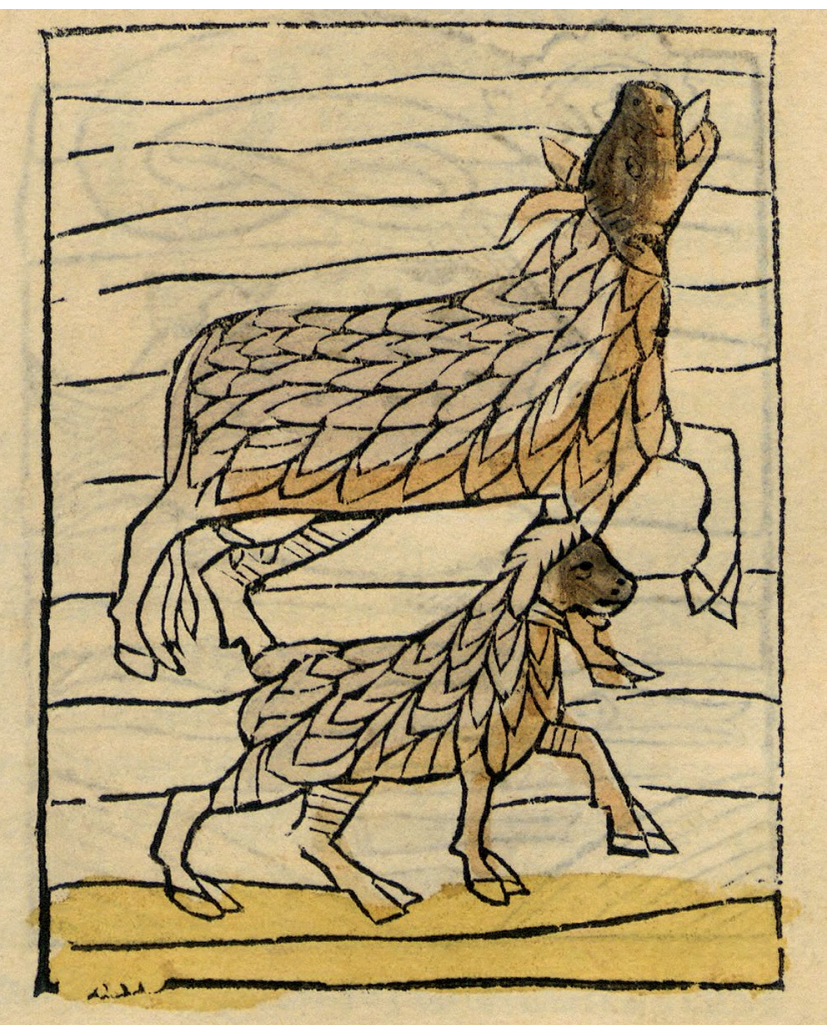

FIG. 4. - Hortus sanitatis 4, 99, Vacca marina (Épernay, BM, Inc. 3017, 1491).

Selon De Saint-Denis (1955), cette tortue d'eau douce est l'Emys lutaria Linnaeus, 1758. Selon Kitchell \& Resnick (1999: 1962, n. 228), ou D’Arcy Thompson (1947: 167, 168), il pourrait s'agir d'une tortue de mer, Testudo coriacea Vandelli, 1761 ou Dermochelys coriacea Linnaeus, 1766.

Examinons maintenant la transmission aristotélicienne, en commençant par la tortue d'eau douce, devenue chez Pline mus marinus. Voici comment Pline réutilise les informations d'Aristote:

«Le rat marin pond ses œufs dans un trou creusé à terre; il les recouvre de terre; le trentième jour il les découvre et emmène à l'eau ses petits [...] Les petits de tous les animaux aquatiques sont aveugles au début de leur vie. » (Plin., nat. 9, 166 [De Saint-Denis 1955: 90])

Pline reprend à Aristote deux éléments : la ponte s'effectue à terre, dans un trou creusé à cet effet; le délai de maturation est de 30 jours. Il en ajoute deux issus d'une autre source; la mère vient chercher ses petits pour les emmener à l'eau; les petits sont aveugles. Ces deux informations sont erronées. Les petites tortues, une fois l'œuf éclos, sortent de leur trou et se dirigent seules vers la mer dès qu'elles perçoivent une baisse de température qui semble indiquer la nuit. Elles y voient dès la naissance.

La remarque de Pline concernant l'accompagnement maternel provient-elle d'une mauvaise interprétation concernant la reproduction des tortues marines? Celles-ci reviennent en effet toujours pondre au même endroit, qui est celui où elles-mêmes sont nées. Cela peut-il par ailleurs expliquer la 
Tableau 1. - L'exemple du rat de mer (mus marinus) dans plusieurs encyclopédies.

\section{Plin., nat. 9, 166}

Le rat marin pond ses œufs dans un trou creusé à terre; il les recouvre de terre;

le trentième jour il les découvre et Tre emmène à l'eau ses petits.

Les petits de tous les animaux aquatiques sont aveugles au début de leur vie.

\section{TC, DNR 7, 55}

Le rat de mer vient à terre et creuseLe rat de mer vient à terre pour dans le sol un trou où il pond ses y pondre ses œufs après avoir $œ u f s$, puis le recouvre de terre.

Trente jours plus tard, il revient, rouvre le trou et accompagne ses petits jusqu'à l'eau.

Dans les premiers temps les petits sont aveugles comme les petits de presque tous les animaux aquatiques. creusé un trou, et il les recouvre de terre.

II revient au bout de trente jours, rouvre le trou et emmène ses

\section{Ces petits sont aveugles dans} les premiers temps, comme les petits de presque tous les animaux aquatiques. petits à l'eau.

\section{AM, DA 24, 81}

Le rat de mer sort de l'eau, creuse un trou dans la terre, y pond ses œufs, les recouvre

et quand, au bout de trente jours, les petits sortent de l'œuf, il revient, déterre sa progéniture et l'emmène avec lui dans l'eau. Les petits sont tout d'abord aveugles et, ensuite, ils acquièrent la vue.

Tableau 2. - L'exemple de la tortue de mer (testudo) dans plusieurs encyclopédies.

\section{Plin., nat. 9, 37}

Elles pondent des œufs semblables à ceux des oiseaux, une centaine environ.

Dans un trou creusé hors des eaux et recouvert de terre, qu'elles tassent et aplanissent avec leur poitrine, elles les couvent pendant la nuit.

Certains croient qu'elles chauffent leurs œufs en les fixant du regard.

Elles les font éclore au bout d'un an (Educunt fetus annuo spatio).

\section{TC, DNR 6, 49}

Sortie à terre, elles pondent des œufs, pareils à des œufs d'oie, au nombre de cent;

elle les enfouit hors de l'eau et les couve avec sa poitrine pendant la nuit.

Certains disent qu'elle ne couve ses œufs que de ses yeux, en les regardant; et cela est tout à fait étonnant, mais la chose est très obscure. Elles veillent sur leurs petits pendant un an (Educant fetus annuo spatio).

\section{VB, SN 17, 131}

Sorties à terre, elles pondent des œufs, jusqu'à cent, pareils à des œufs d'oie.

\section{Et certains disent qu'elle ne les} couve que de son regard.
AM, DA 24, 123

Elles sortent à terre pour pondre des œufs de la taille d'un œuf d'oie, cent ou plus.

La femelle les enfouit dans la terre hors de l'eau, et parfois, la nuit, elle se couche sur eux;

et pour cette raison, certains prétendent qu'elle couve ses œufs du regard, ce qui est faux.

Les tortues de mer veillent sur leurs petits pendant un an et les mènent à l'eau (Fetus autem anni spatio educant et inducunt in aquam). remarque d'Aristote sur l'incubation des tortues terrestres qui dure une année? Du fait que les tortues reviennent pondre tous les ans au même endroit, peut-être a-t-on pu croire qu'elles revenaient chercher leurs œufs.

La transmission des informations de Pline se fait cependant de manière très fidèle chez les encyclopédistes et aucun d'eux n'ajoute quelque précision que ce soit, comme le montre le Tableau 1 (les informations ne variant pas d'une œuvre à l'autre, nous ne donnons que la traduction).

Concernant maintenant l'autre tortue, la tortue de mer, testudo (ou testudo maris Indiae chez Thomas de Cantimpré), ce sont également des informations d'Aristote sur la reproduction qui sont reprises par les encyclopédistes; mais, curieusement, il y a là encore une confusion et ce ne sont pas celles de l'animal concerné qu'on trouve pour la testudo mais celles qu'Aristote rapporte sur la tortue de terre $(\chi \varepsilon \lambda \hat{\omega} \omega \eta \eta)$. Thomas de Cantimpré cependant ne les donne pas par l'intermédiaire de Michel Scot, mais par le biais de Pline, qu'il suit fidèlement à une exception près. L'indication «Les œufs éclosent l'année suivante» donnée par Aristote devient chez Pline educunt fetus annuo spatio (elles les font éclore au bout d'un an) selon la traduction de De Saint-Denis (1955). Or chez Thomas de Cantimpré, on lit: educant fetus annuo spatio (elles élèvent leurs petits pendant un an). On peut certes supposer que educant est le produit d'une mauvaise lecture pour educunt et s'en tenir là. Mais le verbe educare étant utilisé par Thomas de Cantimpré à d'autres reprises (voir supra à propos des phoques), on peut aussi considérer qu'avec le verbe educant, Thomas de Cantimpré donne aux tortues un rôle un peu plus actif que le simple fait de couver, faisant d'elles des animaux capables de veiller sur leurs petits, d'assurer les conditions de leur croissance. À partir de là, quelle valeur donner à l'ablatif annuo spatio? Est-ce, en dépit de la règle classique qui réserve l'accusatif pour la durée et l'ablatif pour la date, mais de manière plausible au Moyen Âge, une indication de durée, qu'il faudrait comprendre comme: "les tortues veillent sur leurs petits pendant un an »? Cette vision pourrait refléter là encore une certaine sensibilité au sort de la petite enfance de la part des encyclopédistes, hypothèse renforcée par la démarche d'Albert le Grand qui va plus loin encore dans la personnification des tortues en précisant qu'elles accompagnent leurs petits à l'eau, information qu'il emprunte à Pline dans un passage consacré au mus marinus. En modifiant très légèrement le texte, Albert le Grand reprend cette précision, alors que Vincent de Beauvais, peut-être suspicieux, s'en abstient, de même qu'il ne mentionne pas la couvaison (Tableau 2). 
Dans la réalité, cependant, il n'existe pas de soin parental chez les tortues. Une seule espèce, la tortue brune de Birmanie (Manouria emys Schlegel \& Müller, 1844), veille sur le nid pendant les premières semaines pour en écarter les prédateurs. $\mathrm{Au}$ bout d'un mois, néanmoins, elle abandonne le nid et les œufs qu'il contient. Le souci parental des tortues est donc un fantasme né au Moyen Âge à partir des observations d'Aristote, signe que les encyclopédistes sont aisément amenés à prêter aux animaux des comportements de parentalité active et attentionnée.

\section{LES PARENTS DÉFENSEURS}

Pour protéger leurs petits, les poissons, dans les textes antiques et médiévaux, recourent à divers procédés. On a vu dans la première partie comment l'allaitement des dauphins se doublait d'un accompagnement pendant l'enfance des petits, accompagnement qui vise aussi à protéger les jeunes tant qu'ils sont fragiles. Ce souci de protection est perceptible dès la ponte des œufs, qui constituent des aliments recherchés par toute sorte d'habitants des eaux. Aussi voit-on quelques espèces de poissons construire des nids pour déposer et protéger leur ponte tandis que d'autres se transforment en gardiens zélés de leur progéniture.

\section{LES POISSONS NIDIFICATEURS}

Le nid des poissons a beaucoup intéressé les savants médiévaux, notamment par l'étonnante correspondance qu'il établit entre le monde des airs, qu'ils connaissent bien, et celui des eaux, qui leur est beaucoup moins familier. Mais si cette attitude trouve une assise réelle indéniable, nous verrons que son attribution à certains poissons est parfois le fruit de contresens ou de mauvaises lectures. Quatre espèces sont décrites comme nidificatrices: chez les céphalopodes, le poulpe, sous les dénominations multipes et le polipus; chez les poissons, le silure (gamanem ou silurus), le labre vert ou l'épinoche marine (phycis) et le trebius.

Concernant la pieuvre, les informations provenant d'Aristote se retrouvent chez ses épigones dans les rubriques consacrées au multipes, tandis que les informations issues de l'Histoire naturelle de Pline sont transmises dans les chapitres consacrés au polypus. Rappelons que les poulpes pondent des œufs englobés dans une masse muqueuse qui a sans doute été prise pour l'œuf lui-même. Ces œufs sont suspendus en grappes au plafond d'une niche rocheuse. La femelle ventile ses œufs et veille sur eux sans s'alimenter pendant tout le temps de la maturation et meurt peu après.

Le texte matriciel d'Aristote concernant le multipes est le suivant:

«Le poulpe s'accouple en hiver, pond au printemps et reste à ce moment-là caché pendant environ deux mois. Il pond des œufs en forme de vrille qui ressemblent au fruit du peuplier. L'animal est très prolifique: car de la masse des œufs naît un nombre immense de petits [...] Il couve $(\dot{\varepsilon} \pi \omega \dot{\alpha} \zeta \varepsilon \mathrm{l})$ quand il a pondu: et c'est pourquoi les poulpes deviennent moins bons, car ils ne cherchent pas de nourriture pendant cette période. " (Arist., $H A \mathrm{~V}$, 12, 544 a7-14 [Louis 1968: 16, 17])
Michel Scot modifie légèrement le texte en le traduisant en latin:

"Animal vero marinum multipes coit in hieme et ovat in vere, et in illo tempore nidificat per duos menses et ovat $[o]$ unum ovulum tantum, simile fructui nucis. Et hoc animal est multe generationis, quoniam ex illo ovo veniunt multi pisces sine numero. [...] Et cum ovaverit femina, sedet super ova, et propter hoc est male carnis isto tempore, quoniam non pascitur neque saturatur." (Arist., HA V, 12, 544 a 7-14 [MS, $H A]$ )

(L'animal marin appelé multipes s'accouple en hiver et pond ses œufs au printemps, et à cette période il couve pendant deux mois et il ne pond qu'un seul œuf, semblable à une noix. Et cet animal a beaucoup de petits, puisqu'il donne naissance à un nombre incalculable de petits [...] et quand la femelle a pondu, elle reste sur ses œufs et pour cette raison elle n'est pas bonne à manger pendant cette période, parce qu'elle ne se nourrit pas et ne se rassasie pas.)

La traduction de Michel Scot, nidificat per duos menses, pousse Thomas de Cantimpré à imaginer un nid:

"Piscis iste in hyeme coit et inter ceteros pisces nidum sibi struit ex surculis. Dicit autem magnus Basilius quod ovum in nido in aqua positum fovet et fetus producit ex eo. Per duos menses ovat, et unum ovum tantum parvumque ad instar nucis. Postquam autem femina ovum ediderit, sedet per quadraginta noctes et fovet id, et consequenti tempore fiunt ex eo pisces innumerabiles.» (TC, DNR 7, 53, De multipede)

(Ce poisson s'accouple en hiver et il est le seul parmi les poissons à se fabriquer un nid de branchages. Mais Basile le Grand dit qu'il couve son œuf posé dans l'eau et que ses petits en sortent. Pendant deux mois il couve et il ne fait qu'un seul œuf, semblable à une noix. Après que la femelle l'a pondu, elle s'installe sur lui pendant quarante nuits et le couve, et par la suite en sortent d'innombrables poissons.)

Sans rien apporter de neuf (nidum ex surculis devient nidum de lignis), Albert le Grand reformule le propos de Thomas de Cantimpré sur ce nid qui n'existe pas:

"Multipes [...] est de genere malakye et de ipso in antecedentibus diximus quod nidum construit de lignis et in ipso spargit ova cohaerentia sibi ad quantitatem nucis." (AM, DA 24, 79, Multipes)

(La pieuvre [...] appartient au genre des poissons, dont nous avons dit, dans les livres précédents, qu'ils construisent un nid de branchages et y déposent leurs œufs; ceux-ci s'agglutinent pour former une boule de la taille d'une noix.)

Concernant le multipes, on assiste donc, au Moyen Âge, à un fléchissement vers l'affectif qu'on a déjà constaté à propos des tortues et qu'on retrouvera ailleurs. Si on peut l'expliquer par les déformations qu'entraînent les différentes traductions (Michel Scot [Van Oppenraaij 1992, 1998] traduit Aristote 


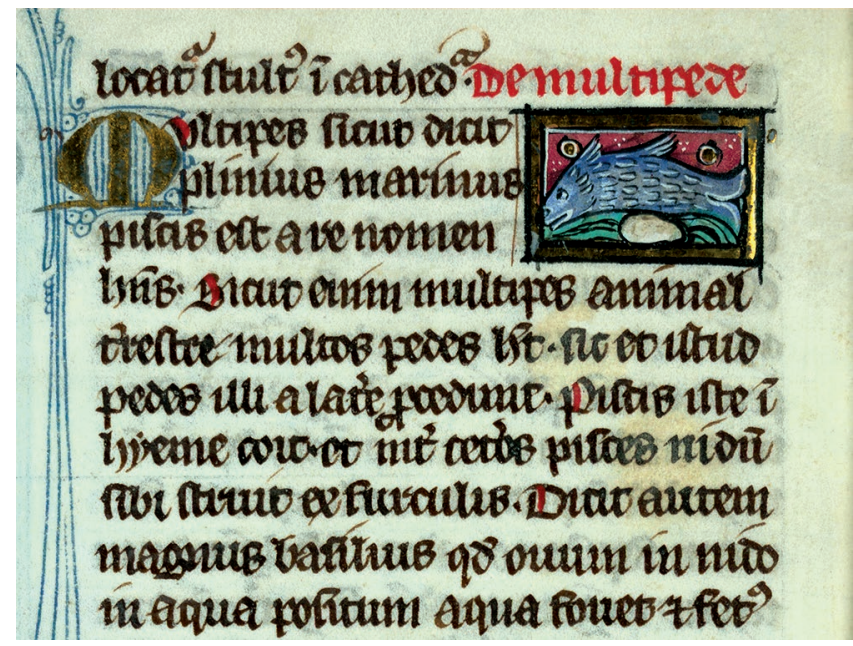

FIG. 5. - Thomas de Cantimpré, Liber de natura rerum 7, 55, De Multipede (Valenciennes, Médiathèque S. Veil, Ms 320, f. 128v).

à partir d'une version arabe et dans un latin assez problématique, truffé de translittérations, qui amène souvent Thomas de Cantimpré à des contresens que reprennent sans barguigner Vincent de Beauvais, Albert le Grand et l'auteur de l'Hortus Sanitatis), on peut aussi supposer que ces lectures sont le reflet des mentalités. Reprenant à leur compte la méthode de l'analogie, qui oriente les livres d'Aristote consacrés à la zoologie (Ribémont 1995: 385-387), les encyclopédistes complètent les observations figurant dans leurs sources sur le comportement parental des animaux marins par des explications qu'ils empruntent au comportement des hommes et des femmes de leur temps. Et ces causes reflètent avant tout l'affection et le soin accordé aux petits.

Le travail des illustrateurs, guidé ou non par les indications marginales (Friedman 2008), souligne l'intérêt porté à l'attachement du multipes pour ses œufs et à sa vigilance assidue dans la couvaison, comme l'attestent certains des manuscrits de Thomas de Cantimpré que nous avons pu observer et l'édition 1491 de l'Hortus sanitatis. Dans les manuscrits de Valenciennes et de Grenade, le multipes est, avec parfois le silure, le seul animal marin représenté avec un œuf. Dans le manuscrit de Grenade, où l'illustrateur n'ajoute jamais quoi que ce soit aux côtés de l'animal représenté, ni accessoire, ni aucun autre animal, le multipes est figuré avec un ouf qu'il enserre dans ses pattes. Dans le manuscrit de Valenciennes, le multipes est couché sur un gros œuf qu'il couve soigneusement (l'indication pour l'illustrateur indique: "un poisson qui couve un petit œuf») (Fig. 5). Dans l'Hortus sanitatis, dont le texte reprend intégralement les indications d'Albert le Grand, le graveur illustre scrupuleusement le texte: le multipes (à l'allure de sauterelle) est installé au-dessus de son nid de branchages, dans lequel repose une masse blanche de forme ovoïde (Fig. 6).

Passons maintenant aux poissons, dont nous n'avons encore pas parlé. Nous traiterons plus loin le cas du silure, qui est à la fois un poisson-défenseur et un poisson nidificateur.

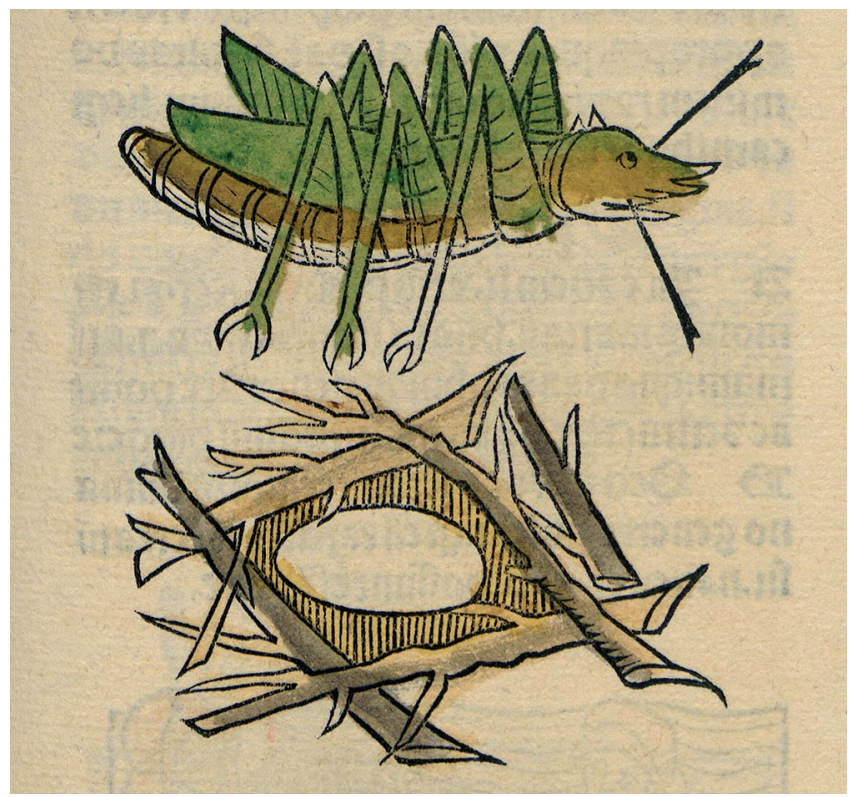

FIG. 6. - Hortus sanitatis 4, 60, Multipes (Épernay, BM, Inc. 3017, 1491; https:// www.unicaen.fr/puc/sources/depiscibus/ui/scans/IMG/hr/60Gd.png, dernière consultation le 24 octobre 2021).

Commençons donc par le phycis, sur lequel les premières informations sont données par Ovide et Pline. Elles sont assez brèves :

"Atque auium dulces nidos imitata sub undis [...]" (Ovide, Hal. 122 [De Saint-Denis 1975: 38])

([le poisson] qui construit sous les eaux des nids douillets ressemblant à ceux des oiseaux [...])

"Mutat et phycis, reliquo tempore candida, vere varia. Eadem piscium sola nidificat ex alga atque in nido parit." (Plin., nat. 9, 81 [De Saint-Denis 1955: 63])

«Le phycis change aussi de couleur: blanc tout le reste de l'année, il est bigarré au printemps. C'est le seul poisson qui se construise un nid d'algues et qui ponde dans un nid.)

Le phycis, dont le nom est diversement orthographié, appartient à la catégorie des labridae, courants dans la Méditerranée. D'Arcy Thompson (1947: 276-278), pense qu'il s'agit d'une des nombreuses sortes de labre, poisson saxatile qui se nourrit d'algues et de petits crustacés. Sa principale caractéristique est en effet qu'il constitue un nid pour y pondre ses œufs. Selon D'Arcy Thompson, cette caractéristique a contribué à entretenir une confusion avec le gobie: ainsi, De Saint-Denis (1967: 86) voit dans le phycis le gobie commun (Pomatoschistus microps Kroyer, 1836) ou l'épinoche marine (Spinachia spinachia Linnaeus, 1758). On possède des vidéos de labres verts tapissant soigneusement d'algues un creux de rocher pour y pondre.

Finissons cette revue des poissons bâtisseurs par le trebius. Ce poisson, qui ne figure pas chez les auteurs de l'antiquité, apparaît sous la plume de Thomas de Cantimpré dans les termes suivants : 
"Mutant colorem candidum in hyeme et fiunt estate nigriores. Inter omnes pisces trebius quidem solus ex alga nidificat et in nido ova parit." (TC, DNR 7, 83)

(Il change de couleur: en hiver, il blanchit, et en été, il noircit. De tous les poissons, il est le seul à fabriquer un nid avec des algues et à pondre ses œufs dans ce nid.)

Cette description résulte d'une double erreur sur Pline commise par Thomas de Cantimpré. D’une part, il prend le nom d'une des sources de Pline, Trebius Niger, pour celui d'un poisson; de l'autre, collectant toutes les informations sur ce trebius, donc quatre phrases dispersées dans l'Histoire naturelle commençant par le nom Trebius, il fait une erreur sur le passage situé en 9, 81 en ne reconnaissant pas le sujet de la première phrase (menae) et en supprimant la phrase où apparaît le sujet des deux dernières, phycis. L'allusion à la nidification du trebius n'est donc autre que la phrase que nous avons déjà citée à propos du phycis. Dans les illustrations du De naturis rerum de Thomas de Cantimpré, c'est le passage sur l'espadon perceur de coques qui a retenu l'attention de l'illustrateur car dans le manuscrit de Valenciennes, l'annotation marginale lui indique de représenter « un poisson qui perce les ne[f]s avec son bec»; on peut penser que la préexistence de l'illustration du gladius ainsi que la confusion phonétique entre trebius et terebral terebrum (le foret, la tarière) ont influé en ce sens: le poisson est montré perçant la coque d'un navire (Fig. 7). Tous les autres manuscrits présentent la même scène. Seul l'illustrateur d'un des manuscrits de Prague (Praha, NK, X.A.4 [cat. 1807]) ajoute un détail prouvant qu'il a lu le texte et ne s'est pas contenté de reproduire une illustration, mais le détail figurant à gauche représente sans doute plutôt un puits avec des pièces d'or couvertes d'eau qu'un nid avec des œufs (Fig. 8). Cependant, quelques siècles plus tard, c'est au caractère affectueux du trebius qu'a été sensible l'illustrateur de l'Hortus sanitatis et la gravure qui montre le parent trebius dressé de toute sa hauteur pour veiller sur un petit poisson qui dort dans un nid au sommet d'un arbre est une des plus séduisantes du recueil (Fig. 9).

\section{LES PARENTS GARDIENS : PROTÉGER, ESCORTER ET DÉFENDRE} Il arrive cependant que nourrir et éduquer ne suffise pas à assurer la survie de la progéniture et que les parents aient besoin de la défendre contre divers ennemis. Thomas de Cantimpré classe d'ailleurs la défense des petits dans les quatre raisons qui poussent les animaux à se battre :

"Fiunt autem quatuor de causis bella in animantibus. Est prima causa naturalis superbia, que in omni animante dominatur. Secunda causa est, propter quam dimicant, cibus, tertia coitus, quarta fetus. Pro fetibus enim inter se dimicant diversi generis animalia sicut gallina cum milvo et anseres cum cornice." (TC, DNR 6, 31)

(Il existe quatre raisons pour lesquelles les animaux se battent: la première est la fierté naturelle, qui prédomine chez tous les êtres vivants; la seconde raison d'affrontement est la nourriture; la troisième concerne l'accouplement, et la quatrième, les petits. Les animaux de toutes les espèces se battent pour défendre leurs petits comme la poule qui affronte le milan et l'oie, la corneille.)

Les poissons n'échappent pas à cette règle. Leur activité de défense prend deux principaux aspects: la protection rapprochée, par exemple lors de déplacements, et la défense du nid, avec tentative d'intimidation d'éventuels prédateurs. Nous étudierons successivement le cas des dauphins, du poisson achandes et du silure.

Chez les dauphins, on voit clairement une volonté de protéger les petits contre d'éventuels prédateurs comme les orques. Un texte d'Aristote, qui a été repris par ses épigones, montre comment un groupe de dauphins adultes accompagne et entoure un groupe de plus jeunes. Un élément pathétique est en outre fourni par la fin du cortège, qui montrent deux dauphins portant le corps d'un petit dauphin décédé, afin qu'il ne soit pas la proie des charognards. Ainsi, la protection des dauphins envers leurs petits est si grande qu'elle concerne aussi bien les vivants que les morts.

«Les petits dauphins sont toujours accompagnés d'un grand, pour assurer leur protection; on a vu un jour une troupe de grands et de petits dauphins qui allaient de concert: et derrière eux, à peu de distance, deux autres apparemment soutenaient tout en nageant, quand il s'enfonçait, un tout petit dauphin qui était mort; ils le soulevaient avec leur dos, comme pleins de commisération, pour empêcher qu'il ne devînt la proie de quelque bête vorace.» (Arist., HA IX, 48, 631a14-20 [Louis 1969: 137])

L'image a marqué les encyclopédistes, non pas tant pour le cortège funèbre, qui n'est pas toujours conservé, que pour le caractère très hiératique des deux gardiens encadrant les jeunes; Thomas de Cantimpré, et à sa suite Albert le Grand et Vincent de Beauvais, ont repris le détail :

"Delphini parvi semper simulsunt tanquam greges et habent duos custodes magnos delphinos. Quod si unus eorum mortuus fuerit, alii efferunt eum super scapulas et custodiunt eum, quoadusque eiciatur tempestate maris ad litus.» (TC, DNR 7, 16)

(Les petits dauphins restent toujours ensemble, comme en troupeau, et ils ont deux grands dauphins comme gardiens. Et si l'un d'eux meurt, les autres l'emportent sur leurs épaules et le gardent jusqu'à ce qu'une tempête le rejette sur le rivage.)

"[...] delphini parvi semper simul sunt tamquam greges et habent duos magnos delphinos custodes.» (VB, SN 17, 109)

([...] les petits dauphins vont toujours ensemble, comme en troupeau, et ils ont deux grands dauphins comme gardiens.)

"Diligit etiam id quod est suae speciei, ita quod pullis eius gregatim ambulantibus custodes delfini magni ponuntur." (AM, DA 24, 40)

(Il aime aussi ceux de son espèce, si bien que, lorsque ses petits se promènent en groupe, deux grands dauphins sont postés près d'eux comme gardiens.) 


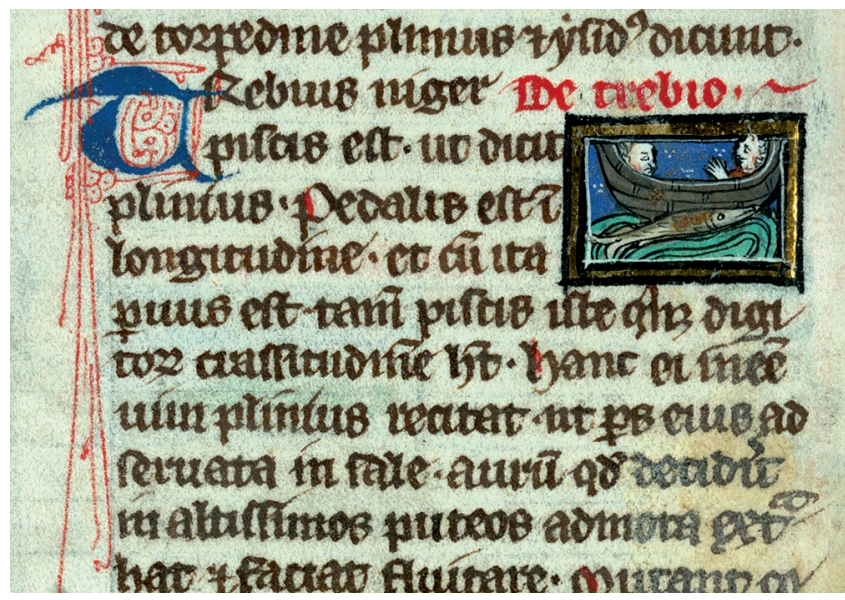

FIG. 7. - Thomas de Cantimpré, Liber de natura rerum 6, 26, De Gamanez (Valenciennes, Médiathèque S. Veil, Ms 320, f. 131v).

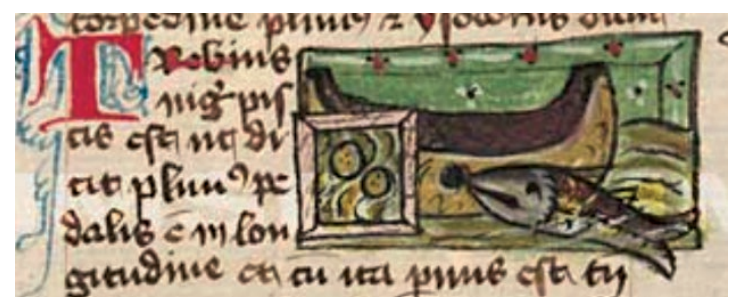

FIG. 8. - Thomas de Cantimpré, De natura rerum Libri XX, 7, 83, De Trebio (X.A.4; Národní knihovna České republiky; Praha; Česko, f. 140r).

À côté des dauphins, on peut mentionner ici le comportement du poisson achandes tel qu'il est décrit par Iorath, si on en croit Arnold de Saxe:

"In eodem Iorach: sicut piscis achandes sollicitus de pullis suis navibus maris aderet, et fiunt immobiles naves omnino propter ipsum.» (AS, DNR II, 7, 26 d 12)

(Toujours chez Iorath: quand le poisson achandes s'inquiète pour ses petits, il se fixe à la paroi des navires; c'est ainsi que des bateaux se retrouvent complètement immobilisés à cause de lui.)

L'exemple est intéressant. Arnold de Saxe est suivi fidèlement par Vincent de Beauvais et par l'Hortus sanitatis. On ne sait pas vraiment ce qu'est l'achandes, mais sa capacité à immobiliser les navires et la parenté possible entre les termes achandes et echineis nous incitent à penser qu'il pourrait s'agir du rémora. Cependant, dans l'abondante documentation fournie par les textes antiques ou médiévaux sur la force d'adhérence admirable du rémora, aucun passage n'explique le comportement de ce poisson par le souci de sa progéniture. On ne voit pas non plus comment rapprocher l'achandes de l'autre animal qui passait pour arrêter les navires, le murex (voir par exemple TC, DNR 7, $31,1)$. Faut-il y voir une invention tardive, qui chercherait à justifier par l'affection parentale un phénomène exposé jusqu'alors sans explication et refléterait une mentalité

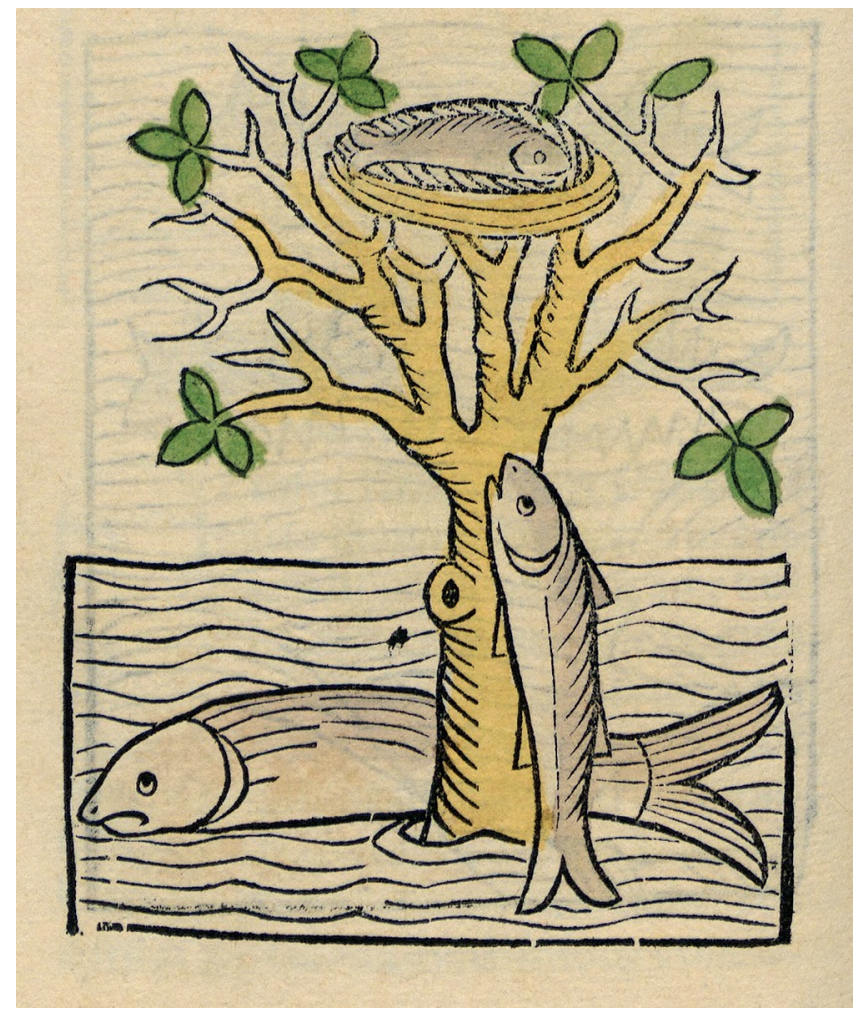

FIG. 9. - Hortus sanitatis 4, 93, Trebius (Épernay, BM, Inc. 3017, 1491; https:// www.unicaen.fr/puc/sources/depiscibus/ui/scans/IMG/hr/93Gd.png, dernière consultation le 24 octobre 2021).

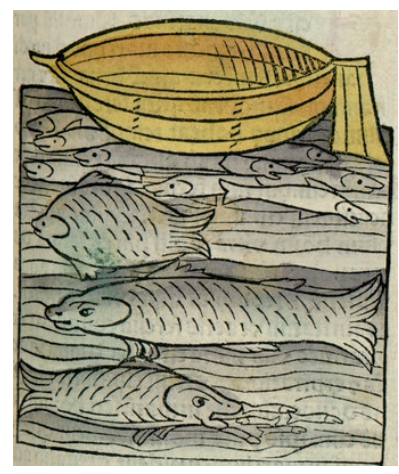

FIG. 10. - Hortus sanitatis 4, 1, Abremon, achandes [...] (Épernay, BM, Inc. 3017, 1491; https://www.unicaen.fr/puc/sources/depiscibus/ui/scans/IMG/hr/1Gd. png, dernière consultation le 24 octobre 2021).

collective attachée au sort des enfants? L'illustrateur de l'Hortus sanitatis a en tout cas a été sensible à ce point du texte en représentant l'achandes entouré de ses petits sous la coque d'un bateau (Fig. 10).

Pour terminer, on trouve une attitude plus agressive avec le silure, qui apparaît sous le terme de $\gamma \lambda \dot{\alpha} v ı$ en grec, glanis ou silurus chez Pline; il devient glanieuz et silurus dans la traduction de Michel Scot, glamanez et silurus chez Thomas de Cantimpré, garcanez et sunus chez Albert le Grand. Aristote consacre plusieurs passages à l'attitude exceptionnelle de ce poisson: 
«Parmi les poissons d'eau douce, le silure mâle prend beaucoup soin de ses petits. En effet la femelle s'éloigne après la ponte, mais le mâle reste à l'endroit où demeure la plus grande quantité du frai et veille sur les œufs. Son assistance se réduit à écarter les autres petits poissons pour qu'ils ne mettent pas à mal sa progéniture. Et il fait cela pendant quarante ou cinquante jours, jusqu'à ce que les petits aient grandi et qu'ils soient devenus capables d'échapper par la fuite aux autres poissons. Les pêcheurs reconnaissent l'endroit où il est en train de veiller sur les œufs; car en écartant les petits poissons il bondit, fait du bruit et pousse un grognement ( $\tilde{\eta}$ xov

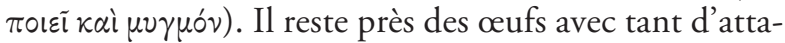
chement qu'il arrive parfois que les pêcheurs, si le frai est fixé sur des racines profondes, l'amènent aussi près que possible : lui cependant n'abandonne pas sa progéniture et, s'il est jeune, il se prend vite à l'hameçon, car il se jette sur les petits poissons qu'il rencontre; s'il a au contraire l'habitude et s'il a déjà mordu à l'hameçon, même dans ce cas il n'abandonne pas sa progéniture, il mord les hameçons de ses dents qu'il a très dures et les détruit. " (Arist., HA IX, 37, 621a21-621b2 [Louis 1969: 106])

"Les œufs les plus lents à se développer sont ceux des silures : aussi le mâle monte-t-il la garde jusqu'à 40 ou 50 jours, pour empêcher les petits poissons qui passent de dévorer sa progéniture.» (Arist., HA VI, 14, 568 b 15-17 [Louis 1968: 93])

«[...] car à l'exception des silures, les autres poissons ne surveillent même pas leurs œufs.» (Arist., HA VI, 14, 569 a 3-4 [Louis 1968: 94])

"Silurus mas solus omnium edita custodit oua, saepe et quinquagenis diebus, ne absumantur ab aliis.» (Plin., nat. 9, 165 [De Saint-Denis 1955: 90])

(De tous les poissons, le silure est le seul mâle à garder les oufs, souvent pendant cinquante jours, pour qu'ils ne soient pas dévorés par les autres.)

Le silure est un cas particulièrement intéressant, car il est très présent dans la littérature savante sur les poissons et les textes écrits à son sujet témoignent d'un glissement intéressant en ce qui concerne l'éthologie. En effet, tous les textes suivent Aristote en ce qui concerne la fonction de garde assurée par le mâle, qui ventile les œufs pour assurer leur survie, la durée de celle-ci, son attitude belliqueuse et ses "cris". Ces derniers sont en réalité des sons produits grâce à un muscle associé à la vessie natatoire du poisson, émis en période de reproduction et bien connus des pêcheurs; mais ils n'existent pas chez les silures. Cependant, à partir de Thomas de Cantimpré, un élément s'ajoute, le silure étant présenté non seulement comme un défenseur mais aussi comme un bâtisseur. Il est vrai que le mâle peut construire une sorte de nid d'herbes, un nid ouvert, mais seulement avant la ponte, si les berges n'offrent pas de racines ou de végétaux sur lesquels déposer les œufs. Cependant, cette précision ne figure pas chez Aristote. Faut-il voir dans l'ajout de Thomas de Cantimpré le reflet d'une erreur de traduction de Michel Scot? Dans la traduction de celui-

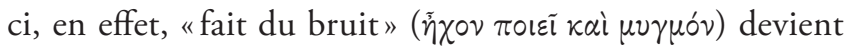
cum orificio suo fecit opus quoddam (il fait un travail avec sa bouche) : soit, ne comprenant pas le texte d'Aristote dans sa version arabe, Michel Scot aurait traduit par une tournure vague, "faire un travail avec sa bouche», soit, influencé par l'exemple d'autres poissons comme l'épinoche marine, il aurait étendu les capacités de celle-ci au silure. À moins que ce ne soit Thomas de Cantimpré qui interprète le terme opus employé par Michel Scot dans le sens d' «ouvrage, édifice, construction»: Cum orificio suo fecit opus devient en effet edificat circa fetus opus quoddam (Il construit un ouvrage autour de ses petits). On peut constater également que le souci instinctif de préserver les œufs, souligné par Pline et Aristote, se colore déjà dans l'Antiquité d'une affectivité marquée à l'égard des petits; celle-ci se renforce encore chez Thomas de Cantimpré : les œufs à protéger deviennent une progéniture que le silure aime et défend jusqu'aux limites de ses forces. Preuve de l'intérêt porté à cette vision des choses, l'illustrateur de l'Hortus a retenu du silure son côté bâtisseur, le montrant au bord de l'eau en train de fabriquer un nid de branchages (HS, ch. Gamanez et gonger).

"Animal autem quod dicitur glanieuz ex piscibus fluvialibus est. Et est mas illius magne sollicitudinis circa suos pullos. Et femina, postquam ovat, dimittit ova sua et vagatur et mas custodit locum in quo sunt ova et stat illic custodiendo ova. Et hoc facit per quadraginta aut quinquaginta dies, quousque crescant pulli et habeant potestatem fugiendi pisces. Et venatores sciunt locum, in quo est iste piscis custodiens pullos; et in tempore in quo proibet pisces appropinquare ovis, facit cum eius orificio opus quoddam et vociferat. Quoniam tantum diligit sua ova quod, si essent in profundo maris, non auferretur ab eis. Et multotiens cadit in rete, et forte comedet fila retis et abscindet ipsa et tamen non dimittet ova.» (Arist., HA IX, 37, 621 a 21-621 b 2 [MS, HA])

(Le glanieuz appartient aux poissons de fleuve. Et le mâle fait preuve d'une grande sollicitude envers ses petits. La femelle, après la ponte, abandonne ses petits et s'éloigne, tandis que le mâle garde le lieu où sont les œufs et il reste là à protéger les œufs. Il fait cela pendant quarante ou cinquante jours, jusqu'à ce que les petits grandissent et qu'ils aient le pouvoir de fuir les autres poissons. Et les pêcheurs connaissent le lieu où ce poisson garde ses petits; et au moment où il empêche les poissons d'approcher ses œufs, il fait un travail avec sa bouche et crie. Il chérit ses œufs à tel point que s'ils étaient au fond de la mer, on ne pourrait l'en écarter. Et il tombe souvent dans des filets, et il mangera les mailles du filet et les rompra et ne négligera pas ses œufs.)

"Glamanez monstrum est, ut dicit Aristotiles quod in aquis fluvialibus manet. Mas istius monstri maximam sollicitudinem habet circa fetus suos; femina autem negligit 
eos et recedit vagaturque per aquas. Tunc masculus pietate naturali motus circa fetus stat iuxta fetus suos, quousque crescant et habeant potestatem fugiendi adversarios pisces. Interim vero pater edificat circa fetus opus quoddam, quo iuventutis tempore tueantur. Ut autem adversarii terreantur, vociferat fortiter; et est sollicitus omni tempore circa eos. Quod si illo tempore contigerit eum casu reti incidere, fortissimis dentibus suis retia scindit et animositate potius evadit ipso tempore sollicitudinis quam fortitudine, quoniam desiderio fetuum animatur ad robur insolitum." (TC, DNR 6, 26, De glamanez)

(Le silure glane est un monstre, à ce que dit Aristote, qui vit dans les eaux des fleuves. Chez ce monstre, le mâle fait preuve d'une grande sollicitude pour ses petits; mais la femelle les néglige, s'éloigne d'eux et part à l'aventure dans les eaux. Alors, mû par un attachement naturel envers ses petits, le mâle reste auprès d'eux jusqu'à ce qu'ils grandissent et qu'ils soient capables d'échapper aux poissons ennemis. Mais parfois le père construit autour de ses petits une sorte d'ouvrage, afin de les protéger pendant leur jeune âge. Et pour effrayer les ennemis, il pousse de grands cris, et il veille constamment sur ses petits. Et si, à cette période, il lui arrive, par malheur, de tomber dans un filet, il le coupe de ses dents très robustes et, dans ce moment d'inquiétude, il s'évade plutôt grâce à son ardeur que grâce à sa force, puisque le désir de retrouver ses petits lui confère une vigueur inaccoutumée.)

Albert le Grand suit Thomas de Cantimpré, qu’il résume en utilisant presque les mêmes termes:

"Garcanez animal dicunt fluviale cuius femina vagabunde discurrens non sollicitatur, sed negligit partum. Mas autem stat circa eos quos femina neglexit. et aedificat etiam in giro circa eos lignis, ne pateat inimicis piscibus, et tunc aliquando extra aquam vociferat fortiter ut sibi adversantia terreantur animalia; et, si in tali sollicitudine cadit in retia, zelo defendendae prolis mordens retia erumpit, non tam fortitudine quam animositate." (AM, DA)

(Le silure glane est, dit-on, un animal de fleuve dont la femelle, vagabondant çà et là, ne se soucie pas de ses petits mais les néglige. Mais le mâle reste près des petits que la femelle a négligés et construit même autour d'eux un rempart de brindilles afin que les poissons ennemis ne puissent les atteindre; et alors il pousse de temps à autre de grands cris hors de l'eau, pour effrayer les animaux qui lui sont hostiles: et si, alors qu'il fait preuve d'une si grande sollicitude, il tombe dans des filets, dans son zèle à défendre sa progéniture il mord les filets jusqu'à les rompre, non tant grâce à sa force que grâce à son énergie.)

Albert le Grand abrège Thomas de Cantimpré en suivant le même ordre que celui-ci. Toutes les informations proviennent d'Aristote. Notons que dans les chapitres intitulés «silure» (TC,
DNR 6, 74, De siluro; AM, DA 24, Sunus), aucune précision supplémentaire n'apparaît; les sources sont le même passage d'Aristote traduit par MS (Arist., HA IX, 37, 621a21 : glanieuz latine silurus ex piscubus fluvvialibus est. [Et est] mas illius magna [sic] solicitudinis circa suos pullos) et deux passages de Pline (nat. 9, 165: Silurus mas solus omnium edita custodit ova, saepe et quinquagenis diebus, ne absumantur ab aliis. Ceterae feminae in triduo excludunt, si mas attigit; nat. 9, 45: silurus grassatur, ubicumque est, omne animal appetens, equos innatantes saepe demergens), repris scrupuleusement par Thomas de Cantimpré puis Albert le Grand:

"Silurus, ut dicit Plinius, piscis est, cui circa fetus mira sollicitudo. Femina enim infra triduum patiente, masculus edita custodit ova quinquagenis diebus, ne assumantur ab aliis. Hic quidem grassatur ubicumque est, animal appetens omne quod quieverit superare.» (TC, DNR 7, 74, De siluro)

(Le silure, à ce que dit Pline, est un poisson qui fait preuve d'une sollicitude étonnante envers ses petits. En effet, alors que la femelle libère ses œufs en moins de trois jours, le mâle monte la garde pendant cinquante jours autour des œufs expulsés pour empêcher les autres animaux de s'en emparer. Le silure rôde n'importe où, en animal à l'affût de tout ce qu'il peut vaincre.)

"Sunus est piscis miro modo sollicitus circa sobolem; emina enim in triduo ovationem complente ${ }^{3}$, mas ova quinquaginta custodit diebus; et omne animal quod appropinquaverit quaerit superare.» (AM, DA 24, 109, Sunus)

(Le silure est un poisson qui se préoccupe de sa progéniture d'une manière extraordinaire. En effet, tandis que la femelle met trois jours à pondre, le mâle garde les œufs pendant cinquante jours; et si un animal approche, quel qu'il soit, il cherche à le vaincre.)

Malgré le changement de nom, peut-être dû à une mélecture de silurus, le sunus d'Albert le Grand est sans conteste le silure glane (Silurus glanis Linnaeus, 1758). Comme dans le livre VII de Thomas de Cantimpré, qui sert ici de source, le chapitre se trouve situé entre ceux consacrés à la stella et au solaris, et Albert le Grand reprend dans l'ordre les informations délivrées par Thomas de Cantimpré.

Les illustrateurs se sont montrés particulièrement sensibles à l'attitude décrite par les encyclopédistes sur le silure, qu'il s'agisse de ceux qui ont illustré les manuscrits de Thomas de Cantimpré ou des illustrateurs de l'Hortus sanitatis. Si le gamanem du manuscrit de Grenade est simplement représenté en train de pousser des cris puisque l'illustrateur de ce manuscrit limite toujours sa représentation à l'animal concerné et à lui seul, les illustrations des manuscrits de Valenciennes (Fig. 11), Prague (Fig. 12), Wrocław (BU, Rehdig. 174, $201 \mathrm{f}$. [XIII/XIVe s.] et Cracovie (Kraków, Biblioteka Jagiellońska, 794 [c. 1440]; Fig. 13) pour cet animal présentent une scène familiale identique, à plusieurs

3. Il y a ici, comme chez Thomas de Cantimpré, un contresens sur le texte de Pline qui parle des femelles d'autres espèces, et non de celle du silure. 


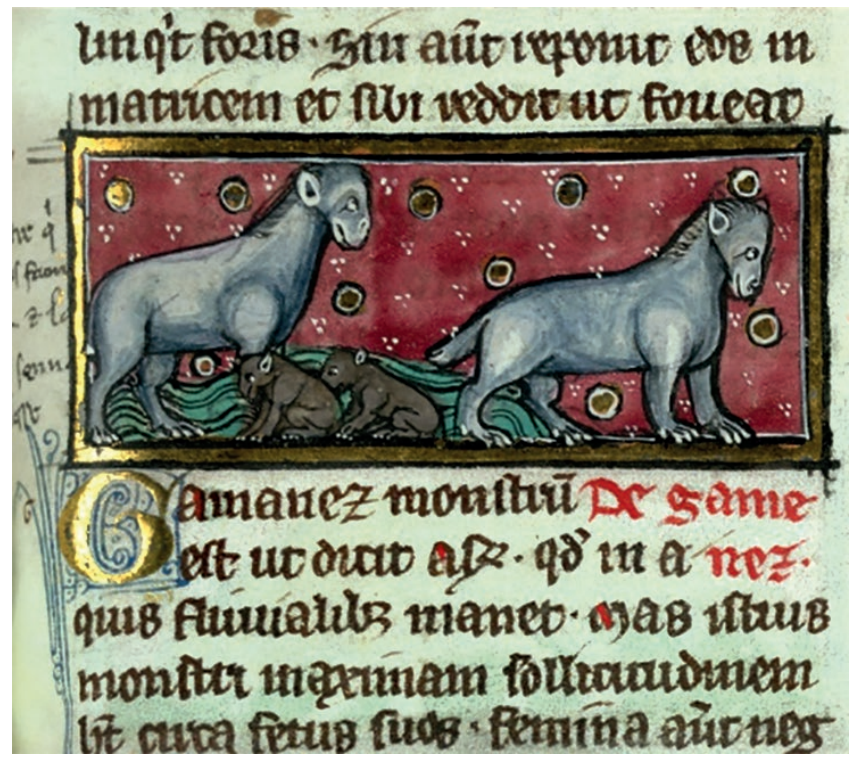

FIG. 11. - Thomas de Cantimpré, Liber de natura rerum 6, 26, De Gamanez (Valenciennes, Médiathèque S. Veil, Ms 320, f. 116r).

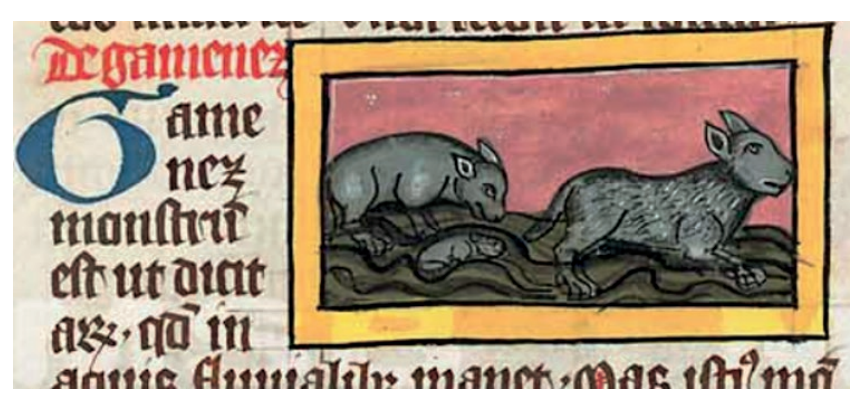

FIG. 12. - Thomas de Cantimpré, De naturis rerum Libri XX, 6, 26, De Gamenez (XIV.A.15; Národní knihovna České republiky; Praha; Česko, f. 87r).

personnages, ce qui est rarissime et demande un vrai talent pour la mettre en place dans une si petite vignette. Le modèle est le même, soit que l'un d'eux ait été le modèle des autres, soit qu'ils aient eu un modèle commun ${ }^{4}$. Le gamenez est représenté comme un quadrupède de type bovin, ce qui est fréquemment le cas avec la mention monstrum (cf. Galalca). La mère tourne le dos et quitte le père. Les deux petits (il ne s'agit pas d'œufs mais de petits quadrupèdes) sont tournés vers le père et se collent à lui dans le manuscrit de Valenciennes; dans les deux manuscrits de Prague, la dimension affective est plus sensible encore: dans le premier, comme dans le manuscrit de Cracovie, le père baisse la tête vers son unique petit en signe de protection et d'affection tandis que, dans le deuxième manuscrit et dans le manuscrit du Vatican, le petit tourne vers son père un regard plein de confiance (Fig. 14). Le manuscrit de Valenciennes a aussi gardé les

4. On ne discutera pas ici de la tradition manuscrite et iconographique du Liber de natura rerum, vaste dossier actuellement exploré par Mattia Cipriani pour la partie textuelle. Nous souhaitons simplement nous limiter à l'étude de quelques vignettes, mais il est clair que bon nombre de manuscrits ont été illustrés à partir d'un modèle initial, reproduit ensuite par les artistes enlumineurs.

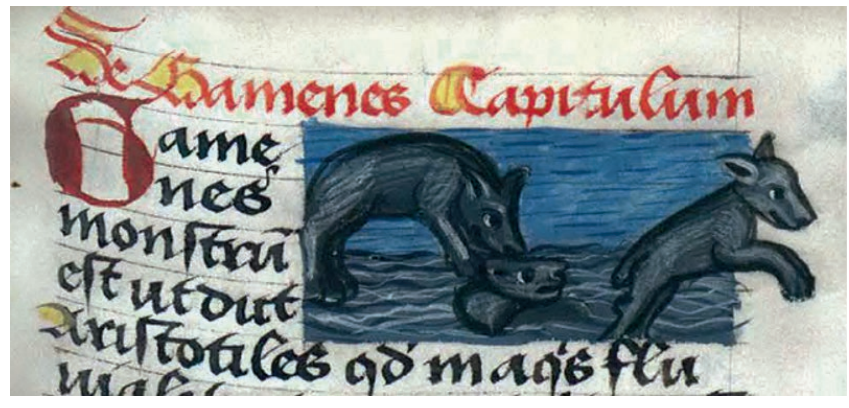

Fig. 13. - Thomas de Cantimpré, Liber de natura rerum (Kraków, Biblioteka Jagiellońska, 794, f. 146 r).

annotations rédigées en langue vernaculaire par le copiste à destination de l'illustrateur, ce qui nous permet de mieux comprendre encore l'intention du peintre, qui a cherché à représenter un «monstre qui garde ses faons en la mer et la femelle senva et les lesse»).

Si l'on passe maintenant au silure, l'illustration du manuscrit de Valenciennes ( «un poisson avec ses œufs» indique la note en vernaculaire destinée à l'artiste) ressemble à celle du multipes et figure un gros poisson couché sur plusieurs œufs (Fig. 15). Un des deux manuscrits de Prague donne à voir un poisson donnant un baiser à son petit, tourné vers lui et qui le regarde (Fig. 16). Quant à l'illustrateur de l'Hortus sanitatis, il n'a pas représenté les petits mais la construction du nid, le gamanem rassemblant avec sa patte les branchages nécessaires pour construire un abri pour ses œufs (Fig. 17). Le nombre et la richesse des illustrations pour ces deux chapitres semblent bien confirmer l'intérêt pour tout ce qui touche aux relations familiales et à l'affectivité déployée entre parents et enfants.

\section{LES PARENTS-ABRIS}

Escorter les petits pour les protéger n'est cependant pas toujours suffisant, comme le prouve la description, chez Pline, d'orques attaquant les baleines et leur progéniture sans que les mères puissent se défendre. Les auteurs de l'antiquité et du Moyen Âge décrivent donc un mode de protection particulier qui consiste, pour les parents, à faire rempart de leur corps jusqu'à abriter les petits en eux-mêmes. Les encyclopédies répertorient quatre types d'abri parentaux à la disposition des jeunes en danger: l'abri du corps parental, utilisé comme un rempart; l'abri de l'étreinte, dans le cas des animaux marins possédant des bras comme les poulpes; l'abri buccal, dans la bouche des parents, et l'abri ventral, qui consiste à faire regagner la matrice aux petits déjà nés. Si l'abri buccal est attesté dans la nature, par exemple chez les cichlidés, qui se réfugient dans la bouche de leur mère en cas de danger, et peut donc être issu de l'observation, le dernier est plus fantaisiste et nous essaierons d'expliquer cette croyance. Notons que les deux types d'abris sont parfois confondus dans une même espèce.

Lutilisation du corps parental comme un rempart est signalée par le seul Barthélemy l'Anglais à propos de la baleine. Au contraire des autres encyclopédistes du XIII ${ }^{\mathrm{e}}$ siècle, comme 


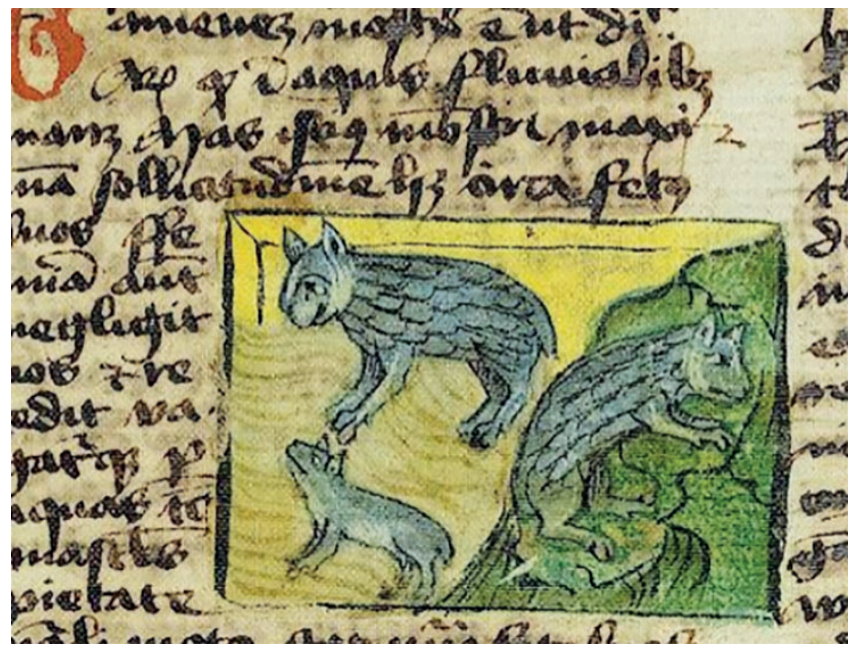

FIG. 14. - Thomas de Cantimpré, Liber de natura rerum (Roma, Biblioteca Apostolica Vaticana, Pal. lat. 1066, f. 111r).

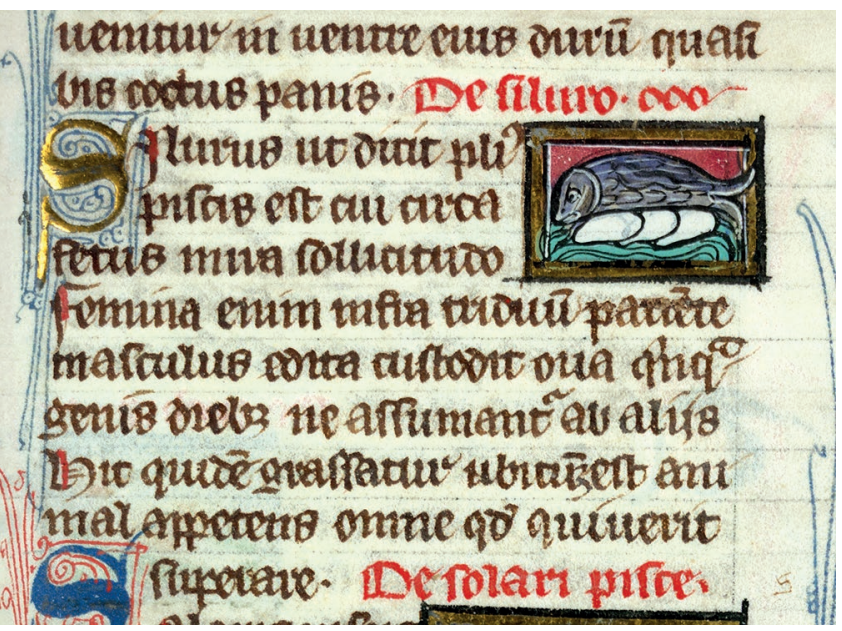

Fig. 15. - Thomas de Cantimpré, Liber de natura rerum 7, 74, De Siluro (Valenciennes, Médiathèque S. Veil, Ms 320, f. 131r).

Thomas de Cantimpré et ses épigones, Vincent de Beauvais et Albert le Grand, Barthélemy ne consacre pas un livre spécifique aux poissons et créatures marines. Il consacre à l'eau le livre XIII de son encyclopédie, le De proprietatibus rerum, et évoque les animaux marins dans le chapitre 26 de celui-ci, où il traite des ornements des flots. Ce chapitre est organisé selon un certain nombre de thèmes (habitat, mouvement, reproduction, alimentation) au cours desquels Barthélemy évoque une trentaine d'animaux aquatiques, dont il expose en général un trait de comportement. La baleine est le seul animal pour lequel il mentionne une attitude parentale, soulignant l'attachement extraordinaire des mères à leurs petits et les différentes manières dont elles les défendent contre les dangers. Les termes sont proches de ceux qu'utilise Thomas de Cantimpré, à l'exception d'un passage, absent chez Thomas : celui où il évoque une méthode (nous verrons les autres plus loin) consistant à abriter les petits dans un lieu protégé et à faire du gigantesque corps maternel un rempart qui les pro-

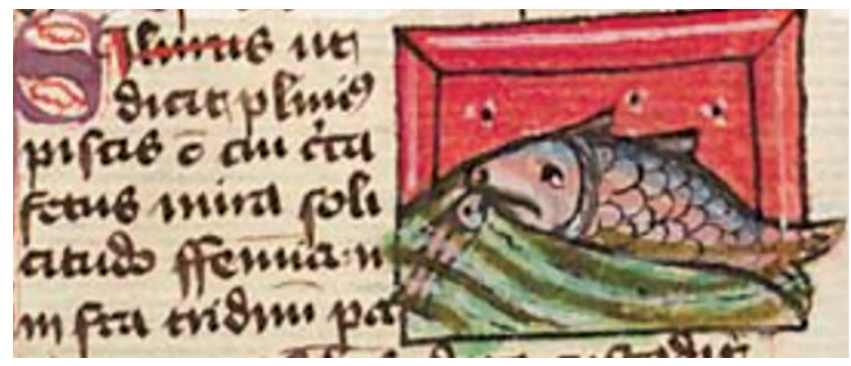

Fig. 16. - Thomas de Cantimpré, De natura rerum Libri XX, 7, 74, De Siluro (X.A.4; Národní knihovna České republiky; Praha; Česko, f. 139r).

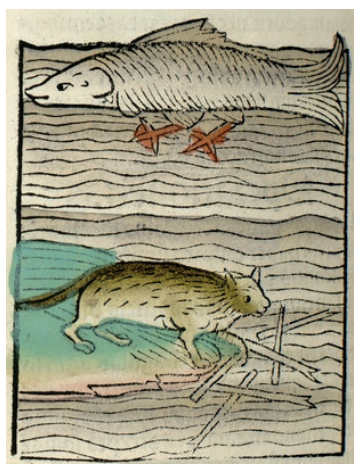

Fig. 17. - Hortus sanitatis, 4, 42, Gamanem et Gonger (Épernay, BM, Inc. 3017, 1491; https://www.unicaen.fr/puc/sources/depiscibus/ui/scans/IMG/hr/42Gd. png, dernière consultation le 24 octobre 2021).

tège des agresseurs. Cependant, le texte pose problème: si opponit pro eorum defensione va bien dans ce sens, inter se et mare ne se comprend pas, et on attendrait plutôt inter eos: en effet, il semble logique de concevoir le lieu sûr (in parte tutiori) comme un port dont la baleine, en faisant barrage de son corps, fermerait l'accès aux assaillants venus du large, mais inter se et mare, signifiant littéralement «entre elle et la mer», n'a pas de sens ici :

"Catulos suos amore miro diligit [...] Contra omnes occursus ipsis nocivos pro eorum defensione opponit, et semper inter se et mare in parte tutiori eos ponit. » (BA, DPR 13, 26, 12)

([La baleine] aime ses petits d'un amour prodigieux [...] Elle fait rempart contre toutes les attaques de ceux qui veulent leur nuire et elle les installe toujours dans un lieu bien protégé entre elle et la mer [?].)

Exerçant un autre mode de défense, le poulpe (multipes ou polypus) fournit un exemple d'abri classique destiné à protéger non les petits mais les œufs. Dans la réalité, comme nous l'avons dit, le poulpe pond des œufs qui forment des grappes, attachées au plafond de son abri rocheux, et la femelle les veille tout le temps de la maturation. Elle exerce notamment une activité très régulière de ventilation des œufs. À partir d'une erreur de Pline, qui imagine la femelle assise sur ses œufs à la manière des oiseaux, différentes variations sont faites à partir du rôle des bras de l'animal qui viennent peu à peu, au fil des déformations du texte, 
enserrer les œufs à la manière d'un filet protecteur. C'est par leur étreinte que les poulpes protègent leurs œufs et, dans la version d'Albert le Grand, la protection des bras devient celle du corps tout entier lorsque le poulpe fait de son corps une chambre pour ses œufs.

"Polypus femina modo in ovis sedet, modo cavernam cancellato bracchiorum inplexu claudit.» (Plin., nat. 9, 164 [De Saint-Denis 1955: 89, 90])

(Tantôt la femelle du poulpe reste assise sur ses œufs, tantôt elle ferme sa grotte en entrecroisant ses bras.)

"[...] polipi sedent super ova sua et incubantes quasi cancellatis brachiis cameram faciunt [...]" (TC, DNR 6, 43)

([...] les poulpes restent assis sur leurs œufs et, en les couvant, ils font comme une chambre de leurs bras entrecroisés [...])

"Feminae aliquando ova incubant, aliquando cavernam cancellato bracchiorum inplexu claudunt." (VB, SN 17, $125,3)$

(Les femelles parfois couvent les œufs, parfois ferment leur abri en entrelaçant et croisant leurs bras.)

\section{"[...] et dum fovet ova sua, quasi de seipso cameram facit} $[\ldots] »(\mathrm{AM}, \mathrm{DA} 24,100)$

([...] et pendant qu'il couve ses œufs, il fait de lui-même une sorte de chambre $[\ldots])$

"[...] superque sedentes et incubantes quasi cancellatis brachiis cameram faciunt $[. .] ».(H S 4,72)$

(Et ils s'installent dessus et les couvent, faisant une espèce de chambre avec leurs bras entrecroisés.)

Nettement plus complexe à étudier est l'abri buccal. Deux animaux aquatiques sont signalés comme concernés par cette pratique: l'abren et la baleine.

Concernant l'abren, nous n'avons qu'une citation : elle vient de Iorach par l'intermédiaire d'Arnold de Saxe:

"Piscis abren hora tempestatis maris natos suos in ventre salvat et post tempestatem evomit eos" (Iorach cité d'après AS, DNR 2, 8, 27c)

(Le poisson abren, en cas de tempête sur la mer, garde ses petits à l'abri à l'intérieur de son ventre et les recrache après le grain.)

Vincent de Beauvais $(S N 17,29,2)$, qui ne cite le livre de Iorach que de seconde main, via le De floribus rerum naturalium d'Arnold de Saxe qui a peut-être été son collaborateur, reprend la citation à l'identique. Si l'on comprend bien le terme evomit, qui dénote toujours un rejet par la bouche, il faut accorder à ventre le sens d'estomac ou, par métonymie, de bouche. L'abren avale donc ses petits et les recrache quand le danger est passé.

Cette citation pose cependant problème. Rien ne nous permet d'identifier le poisson abren, tel qu'évoqué par la citation de Iorach, avec l'athérine, comme Vincent de Beauvais semble l'avoir pensé en rapprochant la citation consacrée à l'abren d'une citation consacrée à l'abaremon (l'athérine). Nous pouvons avancer deux hypothèses pour élucider cette mention, mais qui conduisent à des interprétations très différentes. D’Arcy Thompson (1947: 1, 2), rapproche la forme abren du terme grec àBpauis attesté chez Athénée (Ath. 312 b) et qui, selon lui, serait d'origine égyptienne et pourrait désigner un poisson incubateur buccal, le tilapia (Oreochromis nilotica Linnaeus, 1758), de la famille des cichlidés, très répandu dans les cours d'eau ou les lacs d'Afrique et d'Asie mineure. Les femelles, une fois leurs ovules fécondés par les mâles, reprennent les œufs et les font incuber dans leur bouche où les petits éclosent. Les alevins restent auprès de leur mère jusqu'à ce qu'ils soient capables de trouver leur nourriture et se réfugient dans sa bouche en cas de danger. Dans cette première hypothèse, le De animalibus de Iorach aurait transmis des renseignements inédits fournis par Juba sur le poisson abramis que Vincent de Beauvais aurait à tort interprétés comme un supplément d'informations sur l'athérine. Mais une deuxième hypothèse a été formulée par I. Draelants (2000: 266, 267) qui relève la similitude entre la description du poisson abren tirée de Iorach par Arnold de Saxe et Vincent de Beauvais et un passage de Barthélemy l'Anglais qui concerne le cète (le terme cetus, comme le grec $\kappa \tilde{\eta} \tau o \varsigma$, désigne de façon générique les grands mammifères marins). Barthélemy l'Anglais note ainsi :

"[...] quando inualescit tempestas, foetus suos adhuc iuuenes et teneros, in uentrem suum contrahit, quos serena facta, uiuos euomit iterum et emittit [...]" (BA, DPR Libri XIII, De aqua, ch. 26, De piscibus 1650: 587)

([...] quand une tempête se lève, [le cète] fait rentrer dans son ventre ses petits, encore jeunes et tendres, et, le beau temps revenu, il les recrache vivants et les fait sortir $[\ldots])$

Si nous suivons cette interprétation très plausible, Barthélemy l'Anglais n'aurait pas hésité à traduire par cetus le terme abren qu'Arnold de Saxe se serait contenté de transcrire. On ne peut pas cependant exclure qu'il y ait eu surinterprétation de Barthélemy l'Anglais, influencé par la tradition latine concernant le cète. Il est difficile de trancher alors que l'origine linguistique du mot abren n'est pas encore élucidée avec certitude. Quoi qu'il en soit, les savants médiévaux étaient capables d'imaginer un même scénario pour l'énorme cète, à qui sa taille faisait accorder tous les pouvoirs, et un petit poisson, l'essentiel étant d'assurer une protection fiable aux petits. L'illustrateur de l'Hortus sanitatis a ainsi fidèlement représenté l'abren prenant ses petits dans sa bouche (Fig. 10).

Le rapprochement entre l'abren et le cetus évoqué cidessus nous amène donc à étudier, pour en terminer avec l'abri buccal, les textes concernant la baleine. Le texte matriciel est un passage d'Aristote dans lequel baleine, dauphin et marsouin sont mélangés dans un même groupe d'observations : 
«Le dauphin et le marsouin ont du lait et allaitent leur

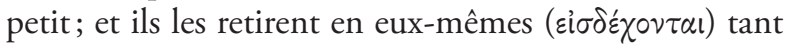
qu'ils sont de taille réduite [...]» (Arist., $H A$ VI, 12, $566 \mathrm{~b}$ 16-23 [Louis 1968: 86, 87])

"Et delfin generat in maiori parte unum, et ad plus duos. Et similiter kalane (baleine) et kokane (marsouin) etiam assimilantur ad delfin [...] Et delfin et kokane habent lac et lactant fetus et cubant [cibant?] eos, dum sunt parvi.» (Arist., HA VI, 12, 566 b 8-20 [MS, HA])

(Et le dauphin a, la plupart du temps, un seul petit, deux au plus. Et de la même manière la baleine et le marsouin ressemblent au dauphin. [...] Et le dauphin et le phoque ont du lait et allaitent leurs petits et les abritent [?] tant qu'ils sont petits.)

Ces deux passages posent problème et sont à l'origine de la légende selon laquelle les baleines accueilleraient leur petit dans leur bouche pour les protéger. Le premier, le développement qu'Aristote ( $H A$ VI, 12, 566 b 16-18) consacre aux phoques et aux marsouins, a été mal lu par les lecteurs et commentateurs d'Aristote, y compris ceux de l'époque moderne, comme l'a montré L. Bodson (1983: 398, n. $19 ; 400,401$, n. 30). Les traducteurs (comme P. Louis) ont semble-t-il mal interprété le verbe grec $\varepsilon i \sigma \delta \varepsilon ́ \chi 0 \nu \tau \alpha \iota$ au sens de "retirer en eux-mêmes", d'où "cacher dans leur ventre", alors qu'il signifiait simplement "accueillir, accepter à leurs côtés". Une observation tout à fait juste d'Aristote sur le comportement parental des dauphins se retrouve ainsi, par sa formulation équivoque, à l'origine d'une tradition fabuleuse qui est sans doute passée facilement aux baleines, dont la taille extraordinaire devait faire croire à leur capacité à ingurgiter leur petit, croyance sans doute renforcée par l'histoire de Jonas. Lorsqu'il a traduit le passage, sans qu'on puisse savoir quel terme était utilisé dans la version arabe d'Aristote, Michel Scot a choisi de

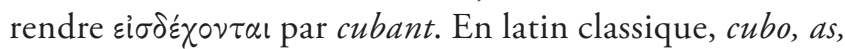
are, cubui n'a qu'un emploi intransitif et signifie "se coucher, s'allonger». Au Moyen Âge, il acquiert aussi un sens transitif qui va signifier "fournir un lit», "s'allonger sur» (au sens sexuel) ou "couver». On peut penser que cubo, au sens de couver, pouvait aussi se comprendre comme "s'allonger près de, couvrir de son corps» et constituer ainsi une allusion à la proximité physique des cétacés et de leur petit. Le terme étant également proche de cibant (nourrir), cubant pourrait aussi résulter d'une mélecture d'un verbe cibant que Michel Scot pourrait avoir utilisé à l'origine. Cibant (nourrir) aurait alors simplement paraphrasé habent lac et lactant fetus, limitant les risques d'erreur. Mais au Moyen Âge, cibo peut aussi signifier «se nourrir, manger, avaler"; cibant eos aurait-il pu être rendu par Thomas de Cantimpré par in ore recipiunt? Reste que la disparition de la source directe de Thomas de Cantimpré, le texte de l'Experimentator, nous oblige à en rester à ces suppositions. Et le texte de Barthélemy l'Anglais, qui reprend les mêmes informations, ne fournit pas d'indice supplémentaire:
"Catulos suos amore miro diligit et eos in pelago tempore circumducit; quod si eos ab arenarum cumulis impedire contigerit, aquae multitudinem in ore collectam super eos fundit, et sic eos a periculo liberans ad profundum pelagi revocat et reducit. Contra omnes occursus ipsis nocivos pro eorum defensione opponit, et semper inter se et mare in parte tutiori eos ponit, et quando invalescit tempestas, foetus suos adhuc juvenes et teneros, in ventrem suum contrahit, quos, serenitate facta, vivos evomit iterum et emittit, ut dicit idem.» (BA, DPR 13, 26, 12)

([La baleine] aime ses petits d'un amour prodigieux et les accompagne dans la mer pendant un certain temps. S'il arrive qu'ils soient immobilisés par une accumulation de sable, elle prend dans sa bouche une grande quantité d'eau qu'elle recrache sur eux; et les libérant ainsi du danger elle les rappelle vers la haute mer et les y ramène. Elle aime ses petits d'un amour prodigieux. [...] Elle fait rempart contre toutes les attaques de ceux qui veulent leur nuire et elle les installe toujours dans un lieu bien protégé entre elle et la mer [?]. Et quand une tempête se lève, [la baleine] fait rentrer dans son ventre ses petits, encore jeunes et tendres, et, le beau temps revenu, elle les recrache vivants et les faits sortir, comme dit le même auteur [Iorach].)

"Balene, ut dicit Plinius, gestant suos fetus quando infirmantur et invalidi sunt; et, ut dicit Experimentator, eos si parvi sunt, in ore recipiunt. Hoc idem facit quando tempestatem viderit imminere; et post tempestatem evomit eos. Quando fetus balene propter defectum aque impediuntur ut matrem non sequantur, mater in ore aquam receptam instar fluvii ad fetus eiicit, ut sic terre liberet inherentes [...]» (TC, DNR 6, 6, De cetho)

(Les baleines, selon Pline, portent leurs baleineaux quand ceux-ci sont faibles et quand ils sont malades, et, selon l'Experimentator, s'ils sont petits, elles les prennent dans leur bouche. Elles agissent de même quand la tempête menace et, après la tempête, elles les recrachent. Et, quand les petits sont empêchés de rejoindre leur mère, les eaux étant trop basse, la mère vomit dans leur direction l'eau qu'elle a conservée dans sa bouche, dans une sorte de fleuve qui délivre ainsi ceux qui se sont échoués [...])

À partir d'Aristote, on trouve des allusions à cette faculté supposée des cétacés dès l'Antiquité, par exemple chez Ambroise (Hexaemeron 5, 7). Cela devient ensuite un lieu commun dans les encyclopédies médiévales comme le montrent les textes de Barthélemy l'Anglais et Thomas de Cantimpré cités ci-dessus, que reprennent bien des auteurs comme Vincent de Beauvais (SN 17, 34 [De balaena]) et l'Hortus sanitatis $(4,14,6)$ ou Olaus Magnus. Une illustration du De gentibus septentrionalibus de ce dernier, intitulée $D e$ mira affectione Balenarum erga foetum (L'admirable affection des baleines envers leur petit), a réuni en une même image les deux attitudes de protection en montrant à la fois la prise d'un petit dans la bouche pour le protéger et les efforts 


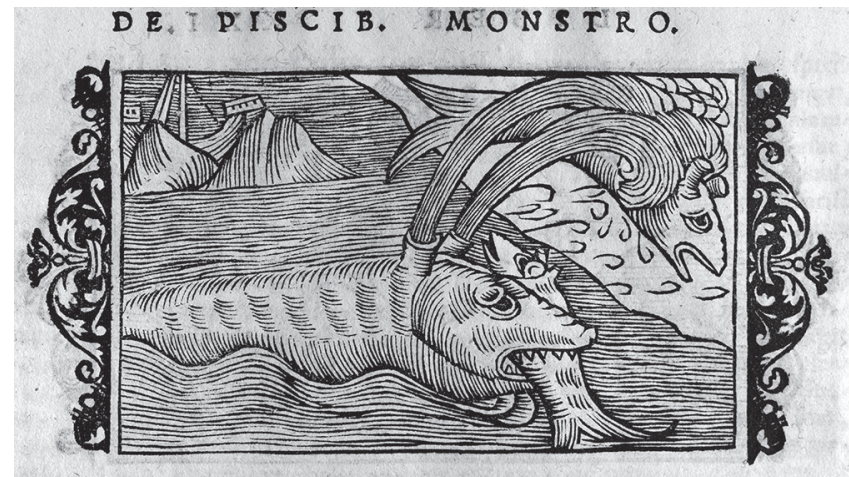

De mira affectione Balenarum erga foetum.

Fig. 18. - Olaus Magnus, Historia de gentibus septentrionalibus. Rome, 1555: 746.

pour dégager un autre petit, échoué, en vomissant de l'eau de mer pour le remettre à flot (Fig. 18).

\section{L'abri ventral des sélaciens}

Les sélaciens sont, de manière générale, dotés par les naturalistes d'une certaine attention aux dangers encourus par leurs petits et ce dès l'antiquité, comme on le voit dans ce texte d'Aristote:

«Les sélaciens déposent leurs petits près de la terre; ils quittent la haute mer et les grands fonds parce qu'ils cherchent la chaleur et craignent pour leurs petits.» (Arist., $H A$ VI, 11, 566 a 23-26 [Louis 1968: 85])

Mais cette attention générale va se trouver renforcée par une attitude spécifique qui a tellement frappé les naturalistes que tous l'ont reprise, voire développée, à la suite d'Aristote, dans la transmission des savoirs. Selon celui-ci, en effet, certaines femelles parmi les sélaciens ont la capacité de reprendre dans leur "matrice» les petits déjà nés lorsqu'il est besoin de les protéger:

"Ainsi donc les autres squales mettent bas leurs petits et les reprennent en eux-mêmes, comme aussi les anges et les torpilles [...] au contraire le squale épineux est le seul à ne pas les reprendre à cause de leur épine. Parmi les poissons plats, la pastenague et la raie ne les reprennent pas à cause des aspérités de leur queue. La baudroie ne reprend pas non plus ses petits, du fait de la grandeur de leur tête et à cause de ses épines. " (Arist., $H A$ VI, 10, 565 b 23-29 [Louis 1968: 84])

Comme l'abri buccal, le phénomène de l'abri ventral trouve son origine dans une observation réelle: en effet, les sélaciens mettent au monde des petits vivants après avoir été ovipares intérieurement. Mais si l'observation d'Aristote est exacte, l'interprétation qu'il en donne est fausse: pensant les alevins issus de l'éclosion des œufs, les anciens, quand ils les voyaient sortir du ventre de la mère, croyaient qu'ils y étaient retournés après la naissance et que celle-ci les avait donc repris, une fois nés. Tenant compte de la morphologie de certains sélaciens épineux, Aristote exclut de l'abri ventral les espèces comme la baudroie ou la pastenague. Michel Scot traduit fidèlement le passage d'Aristote en latin, si on excepte le fait que le terme générique et pluriel $\gamma \alpha \lambda \varepsilon o i$ (les squales) est remplacé par un singulier, galalea, ce qui aura des conséquences par la suite:

"[...] galalea autem extrahit suos pullos extra, deinde red $[d]$ it ipsos iterum sibi; et similiter facit beraki [...]. Et atanitez galeoz tantum non red [d] it pullos ad suum interius propter spinas. Et tangoz et batoz inter pisces amplos non reddit pullos in interius propter duriciem caude. Et nulla rana reddit pullum suum interius propter magnitudinis capitis et spine.» (Arist., HA 565 b 23-27 [MS, HA])

([...] la galalea donne naissance à ses petits, puis les fait rentrer à nouveau en elle-même; et le beraki (translittération de vapkós après le passage par l'arabe?) fait de même [...] et seul le squale épineux ne fait pas rentrer ses petits en lui-même à cause de ses épines. Et parmi les poissons plats la pastenague et la raie ne font pas rentrer les petits en eux-mêmes à cause de la dureté de leur queue. Et aucune baudroie ne fait rentrer ses petits en elle-même à cause de la largeur de leur tête et de leurs épines.)

À partir de là, deux chaînes de transmission se dessinent: Michel Scot, qui rend le nom du squale par des graphies différentes (galeoz/galalea/galatalgalate) et qui transforme le terme générique en un nom d'espèce, sera suivi par Thomas de Cantimpré qui crée une galalca, lui-même repris par Albert le Grand (galalea) et Vincent de Beauvais (galata); parallèlement, une autre chaîne d'information sur cet animal naît à partir d'Ambroise, mais avec le terme mustela. Ce mot, qui désigne la belette chez les animaux terrestres et la lote parmi les poissons d'eau douce, a été choisi par Ambroise comme traduction du grec $\tau \dot{\alpha} \gamma \alpha \lambda \varepsilon \dot{\omega} \delta \eta$ et désigne un squale vivipare (peut-être le Mustelus mustelus Linnaeus, 1758). Les informations sont les mêmes que celles qui sont données par les encyclopédistes médiévaux sur la galata/galalca/galalea. Dans le Speculum Naturale, on trouve ainsi un chapitre Galata et un chapitre Mustela, avec les mêmes informations.

"Alii vivos fetus edunt de suo corpore, ut mustelae, et caniculae, et cete ingentia, delphines, et phocae, aliaque caetera huiusmodi. Quae cum ediderint partus, si quid forte insidiarum terrorisque praesenserint circa catulos suos quemquam moliri, quo tueantur eos, vel tenerae aetatis pavorem materno affectu comprimant, aperire ora, et innoxio partus suos dente suspendere, interno quoque recipere corpore, et genitali feruntur alvo abscondere." (Ambroise, Hexaemeron 5, 3, 7)

(Les autres mettent au monde leurs petits vivants les faisant sortir de leur corps, comme le squale, le chien de mer, les cètes immenses, les dauphins, les phoques ainsi que les autres de ce genre. Et lorsque ces animaux ont mis au monde leurs petits, si, par hasard, ils pressentent qu'il se trame quelque piège ou quelque chose d'effrayant près d'eux, ils calment l'effroi de leur jeune âge par ce geste de tendresse maternelle destiné à les protéger : à ce qu'on 


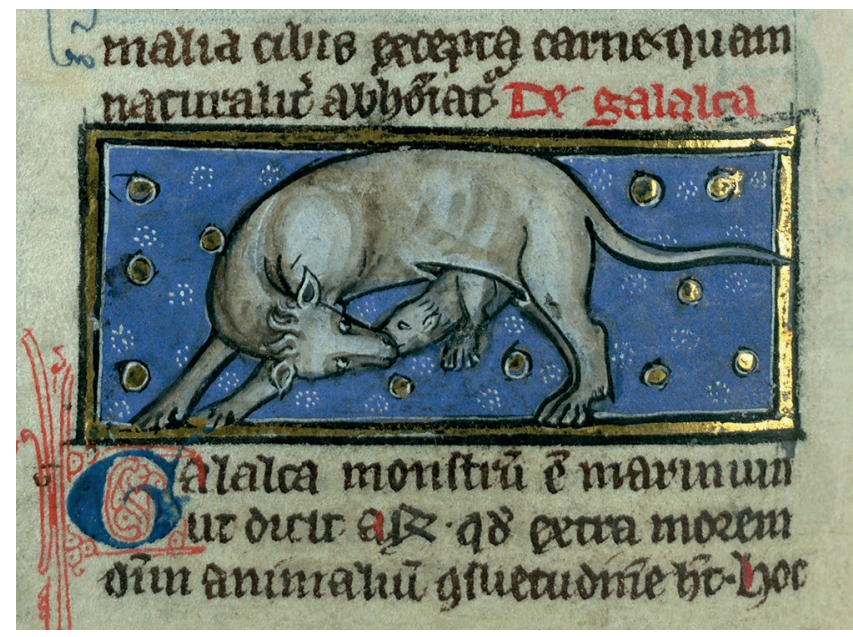

Fig. 19. - Thomas de Cantimpré, Liber de natura rerum 6, 25, De Galalca (Valenciennes, Médiathèque S. Veil, Ms 320, f. 116v).

dit, ils ouvrent leur bouche, retiennent leur progéniture de leurs dents sans les blesser, mais les reçoivent aussi à l'intérieur de leur corps et les dissimulent dans leur ventre.) (trad. F. Bourrema, revue BG)

Il est intéressant de constater que les savants du Moyen Âge, contrairement à leur pratique habituelle (Ribémont 1995: 383-399), cherchent des causes à cette attitude exceptionnelle, alors qu'Aristote n'en donne pas. Thomas de Cantimpré en fait un problème de maturation dans le chapitre galalca, imaginant que la mère, après avoir expulsé ses petits, est capable de les reprendre dans son ventre si elle juge que le développement des petits n'est pas encore achevé, un peu à la manière des marsupiaux qui finissent leur développement dans la poche ventrale de la mère; cette explication est reprise par Albert le Grand et par Vincent de Beauvais. Mais ce dernier, dans le chapitre Mustela, issu de la tradition d'Ambroise, suit sa source en identifiant le danger comme la raison du retour au ventre de la mère et ajoute un autre recours, l'abri buccal, qu'il emprunte sans doute, via Ambroise, à l'abren ou à la baleine.

"Galalca monstrum est marinum, ut dicit Aristotiles, quod extra morem omnium animalium consuetudinem habet. Hoc animal, cum senserit fetus suos in alvo vivere, extrahit eos de ventre suo, non expectans debitum tempus pariendi (ajout). At ubi fetus extraxerit, si quidem ad vitam maturos eos invenerit, relinquit foris. Sin autem, reponit eos in matricem et sibi reddit ut foveat." (TC, DNR 6, 25, De galalca)

(Le squale est un monstre marin, à ce que dit Aristote, qui a des mœurs différentes de celles des autres animaux. Quand cet animal sent ses petits vivre dans son ventre, il les en fait sortir, sans attendre le terme prévu pour la naissance. Et quand il les a sortis, s'il les trouve arrivés à maturité, il les laisse dehors; mais dans le cas contraire, il les réintègre dans sa matrice, et se les rend à lui-même pour les tenir au chaud.)

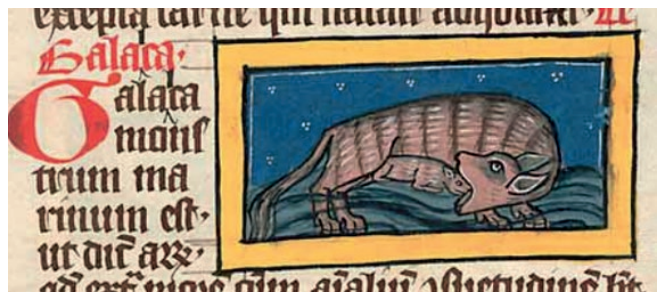

Fig. 20. - Thomas de Cantimpré, De naturis rerum Libri XX, 6, 25, De Galalca (XIV.A.15; Národní knihovna České republiky; Praha; Česko, f. 87r).

"Mustela sicut delphinus et foca vivos fetus de corpore suo edunt. Et, cum partus ediderint, si erga suos catulos insidias quemquam moliri praesenserint, ipsos tuentur, aetatis tenerae pavorem affectu materno comprimunt oraque aperiunt et innoxio dente partus suos suspendunt. Interno quoque corpore recipere ac genitali alvo feruntur abscondere, donec illos ad securitatem deferant aut sui corporis objectu defendant." (VB, SN 17, 74, 6)

(La mustela [chien de mer] ainsi que le dauphin et le phoque mettent directement au monde des petits. Et, lorsque les mustelae [chiens de mer] ont mis bas, si elles pressentent un danger qui menace leur progéniture, elles les défendent, répriment de leur amour maternel la peur de leur jeune âge, ouvrent la bouche et les y retiennent de leurs dents inoffensives. On dit aussi qu'elles les reprennent à l'intérieur de leur corps et les cachent dans leur ventre maternel, tout le temps nécessaire pour assurer leur sécurité ou les défendre en les protégeant de leur corps.)

Parmi les artistes qui ont orné le De natura rerum de Thomas de Cantimpré, plusieurs ont choisi d'illustrer ce fait mais les quatre images que nous présentons ci-dessous (Figs. 19-22) obéissent au même modèle graphique, soit que l'une (peutêtre Valenciennes) ait servi de modèle aux deux autres, soit qu'un modèle commun ait circulé et servi à tous. Comme souvent pour représenter un monstrum, l'artiste responsable de l'illustration d'origine a choisi de représenter un quadrupède de type bovin, qu'on voit de profil, qui fait rentrer dans la cavité ouverte de son ventre un petit dont on ne voit que la partie antérieure. Dans les autres manuscrits (Wrocław, Prague, Cracovie, Rome [Vaticano, Biblioteca Apostolica Vaticana, Pal. lat. 1066, pp., 245 f. (d. 1424; prov. Bavière), f. 1-189v, 20 livres]), on pourrait penser que les illustrateurs ont essayé de représenter le double abri, ventral et buccal : en effet, les mères ont la bouche grande ouverte et sont en train d'y accueillir leur petit, qui alors sortirait du ventre, plus qu'elles ne semblent le repousser dans l'abri ventral. Mais c'est plus vraisemblablement une mauvaise interprétation du dessin de Valenciennes, car le double abri ne figure pas dans le texte de Thomas de Cantimpré.

Au terme de cette partie, il est clair que toutes les descriptions mettant en scène des parents poissons qui font de leur corps un abri reposent sur une observation réelle à l'origine; mais la mauvaise compréhension des termes, la confusion entre les différents animaux et les assimilations entre leurs comportements ont parfois rendu le propos complexe et fantaisiste. 


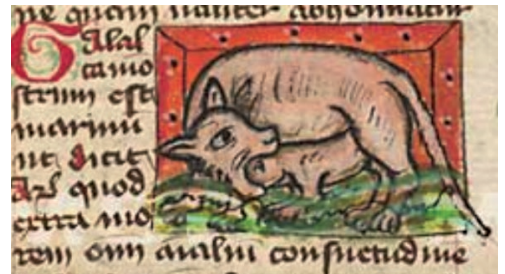

Fig. 21. - Thomas de Cantimpré, De natura rerum Libri XX, 6, 25, De Galalca (X.A.4; Národní knihovna České republiky; Praha; Česko, f. 122r).

Malgré cela, la tendance reste la même que celle que nous avons déjà observée pour d'autres animaux marins: les encyclopédistes et les illustrateurs montrent un intérêt particulier pour tout ce qui concerne les liens parents-enfants, insistant sur le souci de protection et les enjeux affectifs.

\section{LES MAUVAIS PARENTS: OGRES ET INFANTICIDES}

Les animaux aquatiques ne comptent cependant pas que des exemples de bon comportement parental; voyons pour terminer quelques animaux auxquels les encyclopédistes ont prêté des comportements dangereux pour leurs petits.

\section{LE BROCHET}

Même si les Anciens ne le mentionnent guère, puisque la seule occurrence du brochet dans la littérature antique figure dans la Moselle d'Ausone (v. 102-105), la réputation du brochet n'est plus à faire au Moyen Âge et les savants de cette époque, qui connaissent bien ce poisson, ont particulièrement insisté sur sa voracité. Selon eux, la marque la plus perceptible de celleci est qu'il s'en prend à ses propres alevins. C'est ce qu'écrit Thomas de Cantimpré, et il sera repris par Vincent de Beauvais et Albert le Grand, dans des termes proches. Mais là encore, on peut remarquer que la vision des encyclopédistes est très anthropomorphique. Le brochet, en effet, est bien un poisson cannibale, dans la mesure où il mange des brochetons aussi bien que d'autres poissons; mais dans la mesure où il n'y a pas de comportement parental chez le brochet, puisqu'il n'y a pas de nid et que la femelle dépose les œufs çà et là sur les herbes qui tapissent les bords des rivières, on ne peut pas dire qu'il dévore ses propres petits, comme Saturne dévorait ses propres enfants. Interpréter ainsi les choses tient de la déformation anthropomorphique, qui est encore accentuée lorsque Thomas de Cantimpré, qui fait du brochet, mâle ou femelle, un parent cannibale, lie le déplacement de la femelle lors de la ponte à un désir explicite de chasser librement dans sa zone d'habitat, sans risquer de prendre pour pâture ses propres petits:

"Pari generis sui parcere recusat vel ob naturalem crudelitatem vel quia invidus est cibi rapineque impatiens. Qui etiam propria semina, ubi piscis formam susceperint, persequitur. [...] Lucius femina pregnans ascendit aquas quantum potest remotius a loco suo, in quo habitare consuevit, et ibi parit ova, ut flii sui non sint ei impedimentum prede; et hoc propter naturalem crudelitatem, eo quod invidus est cibi rapineque impatiens. Alii dixerunt, quod ascendit aquas propter dulciorem aquam, quia aqua dulcior est semper quanto fonti proximior.» (TC, DNR 7, 48, De lucio)

(Il refuse d'épargner un congénère, soit parce qu'il est naturellement cruel, soit par qu'il est avide de nourriture et assoiffé de victimes. Il s'en prend même à sa descendance, dès lors qu'elle a pris forme de poisson. [...] La femelle brochet, lorsqu'elle a été fécondée, remonte le courant le plus loin possible de l'endroit où elle a l'habitude de demeurer; elle pond là ses œufs afin que ses petits ne constituent pas un empêchement à sa chasse et cela à cause de sa cruauté naturelle, parce qu'elle est avide de nourriture et assoiffée de victimes. D'autres ont affirmé qu'elle remonte le courant parce qu' elle recherche des eaux plus douces, car une eau est d'autant plus douce qu'elle est proche de sa source.)

Si Vincent de Beauvais et l'Hortus sanitatis reprennent les informations données par Thomas, on constate cependant qu'Albert le Grand opère une sélection. Gêné peut-être par le caractère trop anthropomorphique de la première explication, il la laisse de côté et ne reprend que la deuxième, mettant la démarche de la femelle brochet sur le compte de l'instinct de reproduction qui consiste à chercher le meilleur milieu pour ses œufs :

"Lucius piscis est notus dulcis aquae, rostro longo et magni rictus, et fauces habens undique dentibus plenos. Huius cibus sunt pisces, etiam illis qui sunt sui generis non parcens; [...]. Femina huius piscis cum ova spargit, multum ad originem aquarum asscendit propter dulcedinem aquarum quae convenit ovis imperfectis, quae in aquam proiecta incrementum debent accipere." (AM, DA 24, 73, Lucius)

(Le brochet est un poisson d'eau douce bien connu; il a un long rostre, une gueule qui s'ouvre largement et ses mâchoires sont entièrement garnies de dents. Il se nourrit de poissons et n'épargne pas même ceux de son espèce. [...] Quand la femelle de ce poisson pond ses œufs, elle remonte haut vers la source de la rivière à cause de la douceur de l'eau, qui convient aux oufs encore immatures; ceux-ci, une fois pondus dans l'eau, doivent grossir encore.)

\section{FOCA}

On a vu précédemment comment les pinnipèdes étaient considérés comme de bons parents, tant par l'allaitement que par l'accompagnement éducatif qu'ils prodiguent à leurs petits. C'est en tout cas le discours tenu sur le felchus et la vacca marina. Un autre pinnipède, le foca, est cependant décrit comme un animal violent, dont le comportement peut évoquer celui des morses, dont les mâles s'affrontent violemment pour s'assurer la domination sur les femelles. Les informations d'origine sont données par Aristote, qui est mal traduit par Michel Scot: en effet, selon Aristote, les phoques se battent à l'intérieur d'un même sexe, ce qui est exact pour les mâles. Michel Scot commet un contresens et comprend que les mâles affrontent les femelles. À cette première erreur, qu'il reprend, Thomas de Cantimpré ajoute une information qui n'est pas présente à 
l'origine: les unions successives du foca, qui devient une sorte de Barbe-Bleue, éliminant ses femelles l'une après l'autre. Albert le Grand reprend Thomas de Cantimpré et ajoute un dernier élément: l'agressivité du foca s'exerce aussi envers les petits; sans doute le tire-t-il des termes sed suis domesticis utilisés par Thomas de Cantimpré. Si c'est bien le cas, cela semble confirmer l'attention particulière portée à la relation parentale que nous avons observée par ailleurs.

«Les phoques se battent, dit-on, quand ils sont au même endroit, mâle contre mâle et femelle contre femelle, jusqu'à ce que l'un d'eux ait tué ou chassé son adversaire: et tous les petits en font autant. » (Arist., HA IX, 1, $608 \mathrm{~b}$ 24-27 [Louis 1969: 65])

«Et propter hoc dicitur, quod animal, quod dicitur foka, quod semper est in uno loco, semper pugna $[n] t$, ita etiam, quod mas pugnat cum femina, quousque unus interficiat alium et eiciet ipsum; et similiter faciunt filii eorum.» (Arist., HA IX, 1, 608 b 24-27 [MS, HA])

(Et à cause de cela, dit-on, l'animal qu'on appelle foka, qui reste toujours en un même lieu, se bat constamment, au point que le mâle se bat contre la femelle, jusqu'à ce que l'un des deux tue l'autre et l'élimine; et ses petits agissent de même.)

"Focha bos marinus, ut dicit Experimentator, animal fortissimum est in suo genere. Non mutat de facili locum suum, sed sic semper manet in loco, ubi eum natura condiderit. Animal animosum et iracundum est, nec tamen ad alia animantia, sed suis domesticis. Aristotiles: Pugnat enim semper cum femina sua, quoadusque interficiat eam. Interfectam vero eicit a loco et superducit aliam. Nec sic cessat superducere feminas, quoadusque contingat eum propria morte defungi vel a femina sua superatum interimi. Huius pernicie emuli filii vivunt rapina.» (TC, DNR 6, 23)

(Le phoque ou bœuf marin, à ce que dit l'Experimentator, est l'animal le plus fort de son espèce. Il ne change pas facilement de lieu mais reste ainsi toujours dans le lieu où la nature l'a fait naître. C'est un animal impétueux et agressif, non pas, cependant, envers les autres animaux, mais envers ceux de son clan. Aristote: Il se bat en effet constamment avec sa femelle, jusqu'à ce qu'il la tue. Quand elle est morte il se débarrasse de sa dépouille et prend une autre femelle. Et ainsi il ne cesse pas de prendre des femelles jusqu'à ce qu'il meure de sa belle mort ou périsse sous les coups d'une femelle. Ses fils, qui imitent ses vices, vivent de chasse.)

"Foca bos est marinus et est fortissimum animal in genere suo, oppugnans omnia suae speciei animalia ita quod etiam feminam suam interficit; et alii se coniungens iterum illam interficit et sic successive coniungitur multis donec moritur per se vel interficitur ab aliqua feminarum; filios etiam interficit nisi seipsos defendant. Vivit enim praeda et ideo oppugnat compraedatores." (AM, DA 24, 53, Focha)

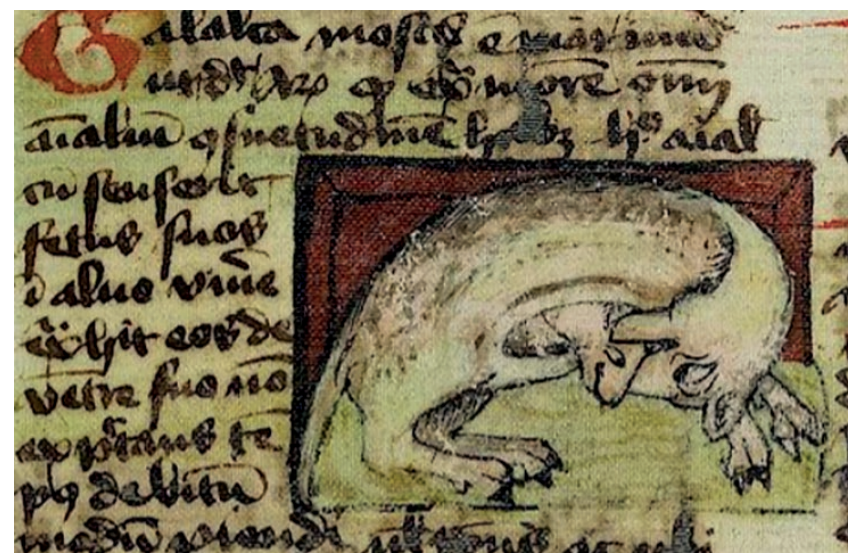

Fig. 22. - Thomas de Cantimpré, Liber de natura rerum (Roma, Biblioteca Apostolica Vaticana, Pal. lat. 1066, f. 111r).

(Le foca est le bouf marin, et c'est l'animal le plus fort de son genre. Il se bat avec tous les animaux de son espèce au point qu'il tue même sa femelle; et, lorsqu'il en prend une autre, il la tue elle aussi et ainsi il s'unit à de nombreuses femelles, l'une après l'autre, jusqu'à ce qu'il meure de sa belle mort ou qu'il soit tué par une des femelles. Il tue même ses petits s'ils ne se défendent pas par eux-mêmes. Il vit de chasse; et pour cette raison il se bat contre ceux qui chassent comme lui.)

Les illustrateurs des manuscrits de Thomas de Cantimpré ont été visiblement sensibles à la violence conjugale mentionnée dans le chapitre Foca. À partir d'un modèle qui est peut-être celui du manuscrit de Valenciennes, dont l'enlumineur a choisi de représenter, dans une scène frontale, un quadrupède de type bovin (un "bœuf marin») doté de mains humaines, comme l'indique le texte, soumettant sa femelle, une main ou un coude sur la tête de celle-ci (Fig. 23), les deux illustrateurs des manuscrits pragois ont repris la scène en l'aggravant, le plus ancien montrant le mâle maintenant la tête de la femelle sous l'eau (Fig. 24), tandis que le plus récent dramatise la scène en ajoutant force gouttes de sang (Fig. 25).

\section{DELPHINUS}

Enfin, on trouve dans le dauphin un cas intéressant car il est révélateur d'un problème de texte. On a vu en effet comment les Anciens soulignent l'attachement du dauphin à ses petits et comment les auteurs médiévaux ont repris et amplifié cette tradition. Or la notice de Thomas de Cantimpré fait le portrait d'un parent à double visage, à la fois père attentif et ogre sans états d'âme:

"Delphini quoque in mari sunt ut dicunt Iacobus et Solinus, belue speciei multiformis. Hiis bestiis nil velocius pelagus habet. Ac nisi infra rostrum os illi foret medio pene in ventre, nullus piscium celeritatem illius evaderet. Sed affert moram in providentia nature, quia nisi resupini atque conversi aliquid capere aut retinere non valent. Mensis decimus partum liberat. Mares autem feminis 


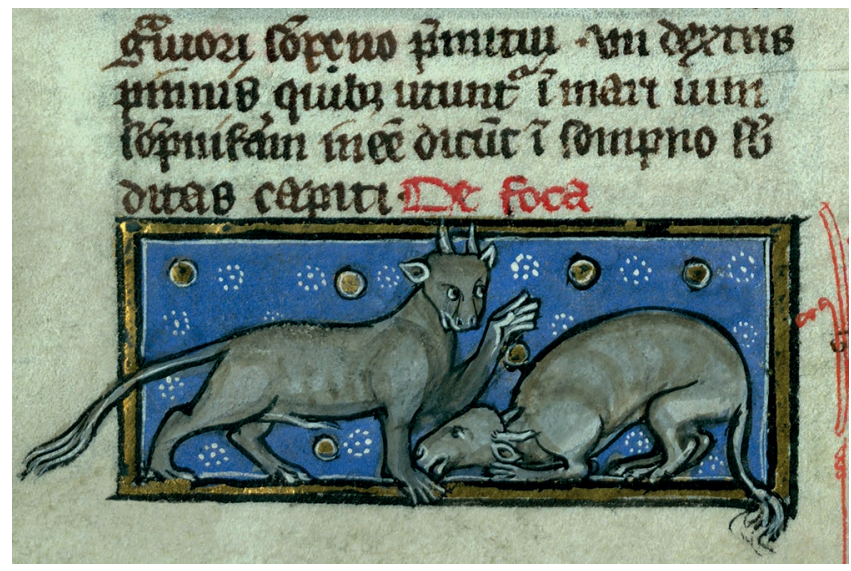

Fig. 23. - Thomas de Cantimpré, Liber de natura rerum 6, 23, De Foca (Valenciennes, Médiathèque S. Veil, Ms 320, f. 116v).

parientibus catulos devorant; sed occultant se matres cum fetibus. Diligunt enim eos tenerrime et longo tempore ducunt post se, et sub aqua sequuntur matrem. At ubi ad robur etatis fetus pervenerint, nisi validi sint, eos etiam matres persequuntur [...] Uberibus fetus alunt. In interim fetus teneros in faucibus suis recipient." (TC, DNR, 6, 16, De delphinis)

(Il y a aussi dans la mer, à ce que disent Jacques de Vitry et Solin, des dauphins, monstres aux apparences très diverses. La mer n'abrite aucune créature plus rapide que ceux-ci. Et s'ils n'avaient la bouche, située sous le rostre, presque au milieu du ventre, aucun poisson n'échapperait à leur rapidité. Mais la providence de la nature les freine, puisqu'ils ne peuvent attraper et garder leurs proies que s'ils sont sur le dos, à l'envers. Le dauphin met ses petits au monde au bout de dix mois de gestation. Lorsque les femelles mettent bas, les mâles dévorent leur progéniture mais les mères se cachent avec leurs petits. Elles les aiment en effet très tendrement et pendant une longue période elles les emmènent derrière elles, et ils suivent leur mère sous l'eau. Mais quand les petits sont parvenus à la force de l'âge, s'ils ne sont pas robustes, leurs mères les accompagnent encore. [...] Les dauphins ne mettent bas qu'en été, jamais en hiver. Les mères allaitent les petits. Parfois elles abritent leurs petits, lorsqu'ils sont tout jeunes, dans leur bouche.)

Thomas fait ici une double erreur. La première s'explique si on se reporte à sa source, Solin :

"Catulos edunt: decimus mensis maturum facit partum: lucinam aestivus dies solvit: uberibus fetus alunt: teneros in faucibus receptant: invalidos aliquantisper prosecuntur" (Solin, Coll. 12, 3)

(Ils mettent au monde des petits. La gestation dure dix mois. Les jours de l'été amènent la délivrance. Ils nourrissent les petits à la mamelle; ils prennent les petits dans leur bouche lorsqu'ils sont jeunes; ils accompagnent quelque temps les petits quand ils sont fragiles.)
Thomas de Cantimpré confond edunt, "mettre au monde» (edere), et edunt, "dévorer"(esse). Après avoir glosé Solin, il complète avec un passage d'Aristote qui lui semble aller dans le même sens; mais là encore, il se trompe. Là où, dans le texte grec, Aristote indique que les dauphins disparaissent pendant trente jours au moment de la canicule:

«Il arrive d'ailleurs que les dauphins disparaissent au moment de la canicule pendant une trentaine de jours. Les petits suivent la mère pendant longtemps, et elle leur est très attachée.» (Arist., HA VI, 12, 566 b 21-23 [Louis 1968: 87])

Michel Scot, dans sa traduction ne garde que quelques mots: ambulat sub pelago (la femelle se promène sous l'eau):

"Et impregnatur per decem menses et parit in estate, non alio tempore, et ambulat sub pelago. Et sequntur ipsum sui pulli magno tempore, quoniam hoc animal diligit suos pullos magno tempore et est longe vite.» (Arist., HA VI, 12, 566 b 21-23 [MS, $H A]$ )

(La femelle porte les petits pendant dix mois; elle met bas en été et se promène sous l'eau. Et les petits la suivent longtemps, parce que cet animal aime ses petits longtemps, et sa vie est longue.)

Thomas de Cantimpré, visiblement, interprète, dans la foulée de son contresens sur edunt, le fait que les petits suivent leur mère (malgré le masculin ipsum) comme une tentative de se cacher pour échapper aux mâles cannibales.

Par la suite, Vincent de Beauvais reprend sans sourciller les informations de Thomas de Cantimpré:

"Solinus: delphini fetunt alunt; teneros in faucibus receptant, inualidos aliquantisper prosequuntur. Ex libro de natura rerum: delphini solo aestatis tempore pariunt, hiberno numquam. Mares feminis parientibus catulos devorant sed matres cum fetibus se occultant. Diligunt enim eos tenerrime longoque tempore ducunt post se et illi sub aqua matres sequuntur. At ubi ad robur aetatis perveniunt, nisi sint validae, eas etiam matres persequuntur. [...] Delphini parvi semper simul sunt tamquam greges et habent duos magnos delphinos custodes.» (VB, SN 17, 26)

(Solin: Les dauphins nourrissent leurs petits; ils les prennent dans leur bouche quand ils sont petits, et les accompagnent quelque temps lorsqu' ils sont faibles. D'après le Livre de la nature des choses: les dauphins ne font leurs petits qu'en été, jamais en hiver. Les mâles dévorent les petits lorsque les femelles les mettent au monde, mais les mères se cachent avec leurs petits. En effet elles les aiment très tendrement, elles les accompagnent pendant une longue durée et les petits suivent constamment leurs mères sous les eaux. Mais quand ils parviennent à l'âge adulte, les mères les accompagnent encore s'ils sont fragiles. [...] Les petits dauphins sont toujours ensemble, comme un troupeau, et ils ont deux grands dauphins comme gardiens.) 


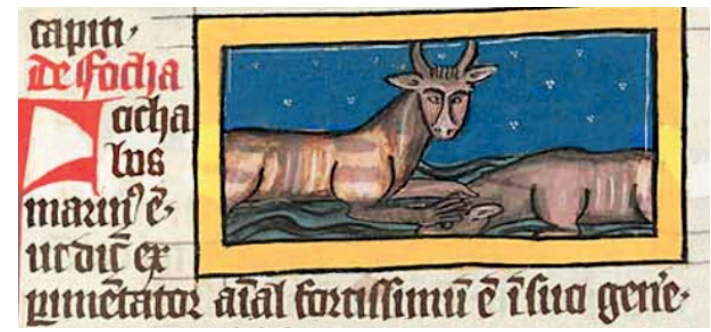

Fig. 24. - Thomas de Cantimpré, De naturis rerum Libri XX, 6, 23, De Focha (XIV.A.15; Národní knihovna České republiky; Praha; Česko, f. 87r).

Mais Albert le Grand, peut-être à la recherche d'une cohérence, sépare les indications entre deux espèces différentes. Il fait du dauphin un animal doux et gentil, doté des comportements qu'on attribue d'ordinaire à cet animal (père attentif y compris aux petits des autres, protecteur, mères affectueuses, allaitantes, prenant les petits dans leur bouche en cas de danger) : c'est l'objet du chapitre Delphinus. Parallèlement, empruntant à Thomas de Cantimpré un autre animal, Delphinus alterius generis, il supprime les informations données par Thomas à son propos et injecte à la place, dans ce chapitre, les informations sur l'agressivité du dauphin envers ses petits. Il va même jusqu'à ajouter une précision de son cru qui est que les femelles, au bout d'un temps, s'en prennent elles aussi à leurs petits, qui se trouvent alors en danger s'ils n'ont pas acquis la force nécessaire pour parer l'agressivité maternelle:

"Delphinorum quorundam genus aliud in Nilo flumine est, quorum dorsa cristas habent serratas. Hii delphini cocodrillos studio eliciunt ad natandum natantesque sub undis astutia fraudulenta decipiunt et occidunt. Nam cocodrillorum teneros ventres serratis cristis secant, et interimunt." (TC, DNR 6, 17)

(Le dauphin d'une seconde espèce: il y a, dans le Nil, une autre espèce de dauphin [l'aiguillat?], dont le dos est pourvu de crêtes acérées. Ces dauphins poussent vivement les crocodiles à aller nager et, nageant eux-mêmes sous l'eau, ils les trompent et les tuent par une astuce frauduleuse. En effet ils incisent de leurs crêtes acérées les ventres tendres des crocodiles et les font périr.»

"Delfinus alterius generis: Est autem aliud delfinorum genus, de quo narrant quod habet os in medio sui corporis et tantae est celeritatis quod nichil ipsum marinorum evaderet nisi quod capit praedam conversum ita quod ab inferiori os supra convertit, et tunc pisces fugere possunt; et hoc genus odit pullos suos, ita quod masculus devoraret eos nisi femina eos occultaret; mater igitur occultat pullos et secum ducit usque ad completionem; et postquam completi sunt, ita eos odire incipit quod cum mare devoraret eos si se viribus propriis non defenderent.» (AM, DA 24, 40)

(Il existe un autre genre de dauphin à propos duquel on raconte qu'il a la gueule au milieu du corps; il est si rapide qu'aucun animal marin ne lui échappe; mais il attrape ses proies sur le dos, de manière à avoir sa gueule, qui est dessous, tournée vers le haut, et alors les poissons

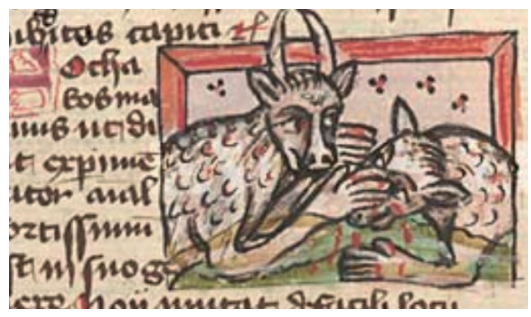

Fig. 25. - Thomas de Cantimpré, De naturis rerum Libri XX, 6, 23, De Focha (X.A.4; Národní knihovna České republiky; Praha; Česko, f. 121v).

peuvent fuir; ce genre de poisson hait ses petits, si bien que le mâle les dévore si la femelle ne les cache pas: la mère cache donc ses petits et les emmène avec elle jusqu'à ce qu'ils aient atteint leur taille adulte; et quand ils sont devenus adultes, elle commence à les haïr à tel point qu'elle les dévorerait avec le mâle si les petits ne se défendaient pas avec leurs propres forces.)

Ces comportements sont rares, et soulignés comme particulièrement cruels et contre-nature. Dans la mesure où ils sont créés, par suite de contresens, à partir des sources antiques, peut-être sont-ils porteurs d'une subjectivité reflétant la haine de l'infanticide présente dans la société médiévale (AlexandreBidon \& Lett 1997: 33-36).

\section{CONCLUSION}

L'intérêt des encyclopédistes médiévaux pour les liens qu'entretiennent parents et petits chez les animaux marins est indéniable même si, à l'exception du silure, les poissons sont nettement moins concernés que les cétacés, qui sont toujours décrits en des termes anthropomorphiques et dont l'amour pour les petits est souvent caractérisé comme extraordinaire. D'une part, les éléments provenant des sources antiques à ce sujet sont repris sans exception. De l'autre, cette attention parentale aux petits est décrite en termes relevant du domaine affectif et fait généralement l'objet d'une amplification dans le lexique, comme on peut le voir chez Thomas de Cantimpré ou Barthélemy l'Anglais. Par ailleurs, les moralisations donnent les cétacés en exemple aux humains. Enfin, bien des éléments qui restent mystérieux dans le comportement animal, comme la reproduction des sélaciens, font l'objet d'hypothèses de la part des encyclopédistes et ces hypothèses reposent sur l'affection des parents envers leurs enfants. Les illustrations viennent confirmer ce constat. S'il est sûr que le peintre, guidé ou non, saisit le trait de comportement le plus propre à susciter une illustration remarquable, il est évident que lorsque plusieurs choix sont possibles, c'est la sollicitude envers les petits qui emporte la préférence, au même titre que l'interaction avec l'homme. Ce choix peut même être fait alors qu'il entraîne des difficultés de représentation, par exemple lorsque la scène nécessite de représenter plusieurs animaux. Tous ces éléments nous permettent de répondre par l'affirmative à la question initialement posée et à suggérer que 
les œuvres des encyclopédistes, sur le point précis que nous avons étudié, constituent bien le reflet d'une attitude sociale répandue. Mais cette étude nous a aussi permis de faire un autre constat sur l'écriture des encyclopédistes: dans un cadre de pensée où la psychologie est encore balbutiante, et où par conséquent, les concepts de psychologie animale et d'instinct ne peuvent encore naître, on cherche cependant déjà à expliquer les comportements décrits par les sources antiques; dans la majorité des cas, c'est l'analogie avec l'homme qui fournit l'explication, et le comportement des animaux marins envers leurs petits est attribué à l'affection. Barthélemy l'Anglais va jusqu'à établir un équivalent de l'âme chez les animaux, qu'il appelle le cœur, siège des instincts naturels mais aussi des affects, parmi lesquels il compte au premier rang l'amour des petits et les soins parentaux. Cette étude montre une fois encore que loin d'être seulement des compilateurs, les encyclopédistes médiévaux ont su insuffler à leur œuvre une réelle nouveauté, tant dans le contenu de leurs écrits que dans leur appréhension de ce qui deviendra l'éthologie.

\section{Remerciements}

Tous mes remerciements vont aux professeurs J. Leclercq-Marx et B. Van den Abeele pour leur précieuse relecture ainsi que pour la précision et la qualité de leurs remarques, qui m'ont grandement aidée à améliorer la qualité de cet article. Merci également à J.-F. Hannequart, conservateur de la médiathèque de Valenciennes, pour son aide dans la lecture du Liber de natura rerum.

\section{RÉFÉRENCES}

\section{SOURCES}

ALBERT LE GRAND: voir STADLER 1920.

[AMBROISE]. - Sancti Ambrosii opera pars prima qua continentur libri Exameron, De Paradiso, De Cain et Abel, De Noe, De Abraham, De Isaac, De bono mortis. C. Schenkl (éd.), Prague, Academiae Litterarum Caesareae Vindobonensis (CSEL ; 32, 1), 1897. AS

ARNOLD DE SAXE: voir STANGE 1906.

ATHÉNÉE: voir PEPPINKI 1937, 1939.

[BARTHÉLEMY L'ANGLAIS] a. - De Proprietatibus rerum fratris Bartholomaei Anglici, de Ordine Fratrum minorum. Berthold Ruppel, Basel, c. 1479-1480.

[BARTHÉlEMY L'ANGLAIS] b. - Bartholomaei Anglici De genuini rerum coelestium terrestrium et infrarum rerum proprietatibus libri XVIII, Francofurti, apud Wolfangum Richterum. [Wolfgang Richter, Francfort], 1650.

CicÉron : voir AUVRAY-ASSAYAS 2018.

PLINE: voir SAINT-DENIS 1955.

SOLIN : voir MOMMSEN 1965.

ThOMAS DE CANTIMPRÉ a. - Liber de natura rerum. Valenciennes, Médiathèque S. Veil, 320, pc., 198 f. (xirre s.; prov. St-Amand OSB).

Thomas de CANTIMPRÉ b. - [Codex granatensis] De natura rerum, de Tomás de Cantimpré. De avibus nobilibus. Tacuinum sanitatis, de Ibn-Butlán. Biblioteca Universitaria y Provincial, Granada, C-67, 116 f. (c. 1440; prov. Vienne).

ThOMAS De CANTIMPRé c. - De naturis rerum Libri XX. Národní knihovna České republiky, Praha, NK, XIV.A.15, 235 f. (xIVeXve s.; [1375-1400 (?); prov. Plzen (?)].
Thomas de CANTimpré d. - De natura rerum Libri XX. Národní knihovna České republiky, Praha, X.A.4, 202 f. (d. 1404; prov. Johannes Rabenstein, Bohême), f. 6-195v.

Thomas de CANTIMPRÉ e. - Liber de natura rerum. Biblioteka Jagiellońska, Kraków, 794, 256 f (xve s. ; prov. Miklosz de Cracovia).

Thomas de CANTIMPRÉ f. - Liber de natura rerum. Biblioteca Apostolica Vaticana, Vatican, Pal. lat. 1066, 245 f. (d. 1424; prov. Bavière), f. 1-189v.

ThOMAS DE CANTIMPRÉ g. - Liber de natura rerum. Biblioteka uniwersytecka we Wrocławiu (olim), Rehdig, 174, $201 \mathrm{f}$. (XIII'-XIVe s.).

([Ho]rtus sanitatis, in inclita civitate Moguntina, Jacobus Meydenbach, 1491. Médiathèque Simone Veil, Epernay, BM, Inc. 3017).

[Olaus Magnus]. - Historia de gentibus Septentrionalibus [...], Autore [sic] Olao Magno Gotho Archiepiscopo Upsalensi Suetiae \& Gothiae Primate. Cum indice locupletissimo. Romae M.D.LV, Impressum Romae apud Ioannem Mariam de Viottis Parmensem, in aedibus Divae Brigittae nationis Suecorum et Gothorum [...] (Caen, BU, cote 11052).

[VInCENT DE BEAUVAIS]. - Bibliotheca mundi; Vincentii Burgundi, ex ordine praedicatorum venerabilis episcopi Bellovacensis, speculum quadruplex, naturale, doctrinale, morale, historiale [...], Duaci, Ex officina Typographica Baltazaris Belleri sub circino aureo [Douai, Baltazar Bellerus], 1624. Vol. 1, livre XVII, col. 1249-1324. [reimpr. Akademische Druck- und Verlagsanstalt, Graz, 1964].

BIBLIOGRAPHIE

AleXandre-Bidon D. \& LeTT D. 1997. — Les enfants au Moyen Age: Ve-XVe siècles. Hachette Littératures (coll. La Vie quotidienne), Paris, $275 \mathrm{p}$.

ArIÈs P. 1975. - L'enfant et la vie familiale sous l'Ancien Régime. Le Seuil (coll. Point Histoire), Paris, 316 p.

Auvray-Assayas C. (trad.) 2018. - Cicéron, La nature des dieux. Les Belles Lettres (Coll. La roue à livres; 43), Paris, xxiv + $262 \mathrm{p}$.

BODSON L. 1983. - Aristotle's statement on the reproduction of sharks. Journal of the History of Biology 16 (3): 391-407. https:// doi.org/10.1007/BF00582408

CallataŸ G. DE \& VAN DEN ABEele B. (éds) 2008. - Une lumière venue d'ailleurs: héritages et ouvertures dans les encyclopédies $d u$ Moyen Âge. Actes du colloque de Louvain-la-Neuve, 19-21 mai 2005. Brepols (coll. Reminisciences; 9), Turnhout, xi +298 p. https:// doi.org/10.1484/M.REM-EB.6.09070802050003050300070304

Clark W. B. (éd., trad., comm.) 2006. — A Medieval Book of Beasts: The Second-Family Bestiary. Commentary, Art, Text and Translation. Boydell \& Brewer, Woodbridge, 344 p.

DraelantS I. 2000. - Le dossier des livres «sur les animaux et les plantes" de Iorach: traditions occidentale et orientale, in Draelants I., Tihon A. \& VAN Den Abeele B. (éds), Occident et Proche-Orient: contacts scientifiques au temps des croisades. Actes du colloque de Louvain-la-Neuve, 24 et 25 mars 1997. Brepols, Turnhout: 191-276. https://doi.org/10.1484/M.REM-EB.3.940

FrIEDMAN J. 2008. — «Monstres qui a ii mamelles bloe»: illuminator's instructions in a MS of Thomas of Cantimpre. Journal of the Early Book Society for the Study of Manuscripts and Printing History 7: 11-32.

Kitchell K. F. \& Resnick I. M. 1999. - Albertus Magnus On animals: a medieval summa zoologica. Johns Hopkins University Press, Baltimore, $2112 \mathrm{p}$.

LECLERCQ-MARX J. 2002. - Du monstre androcéphale au monstre humanisé. A propos des sirènes et des centaures, et de leur famille, dans le haut Moyen Âge et à l'époque romane. Cahiers de Civilisation médiévale 45 (177): 55-67. https://doi.org/10.3406/ ccmed.2002.2820

LeClerCQ-MARX J. 2006. — L'idée d'un monde marin parallèle du monde terrestre: émergence et développements, in CONNOChie-Bourgne C. (éd.), Mondes marins du Moyen Âge. Presses universitaires de Provence (coll. Senefiance), Aix-en-Provence: 259-271. https://doi.org/10.4000/books.pup.3845 
LETT D. 2000. - Famille et parenté dans l'occident médiéval, veXVe siècle. Hachette (coll. Carré Histoire), Paris, 255 p.

LouIs P. (éd., trad.) 1964. - Aristote. Histoire des animaux. Tome 1, Livres I-IV. Les Belles Lettres (coll. des universités de France Série grecque - coll. Budé; 164), Paris, lv + 341 p.

LouIs P. (éd., trad.) 1968. - Aristote. Histoire des animaux. Tome 2, Livres V-VII. Les Belles Lettres (coll. des universités de France Série grecque - coll. Budé; 186), Paris, 325 p.

Louis P. (éd., trad.) 1969. - Aristote. Histoire des animaux. Tome 3, Livres VIII-X. Les Belles Lettres (coll. des universités de France Série grecque - coll. Budé; 189), Paris, 369 p.

Mommsen T. (éd.) 1965. - C. Iulii Solini Collectanea rerum memorabilium. Weidmann, Berlin, $276 \mathrm{p}$.

Peppinki S. P. (éd.) 1937. - Athenaei Dipnosophistarum epitome, ex recensione S. P. Peppinki. Pars prima, Libri III-VIII, Accedit spicilegium Aeschyleum. Brill, Leyden, xxxii + 181 p.

PePPINKI S. P. (éd.) 1939. - Athenaei Dipnosophistarum epitome, ex recensione S. P. Peppinki. Pars secunda, Libri IX-XV, Accedit index personarum locorumque in Peppinki operibus laudatorum. Brill, Leyden, $180 \mathrm{p}$.

RiBÉMONT B. 1995. - L'encyclopédie médiévale et la notion d'instinct animal, in RiBÉMONT B., De natura rerum, études sur les encyclopédies médiévales. Paradigme (coll. Medievalia; 18), Orléans: 383-399.

SAINT-Denis E. DE (éd., trad.) 1955. - Pline l'Ancien, Histoire naturelle. Livre IX, Des Animaux marins. Les Belles Lettres (coll. des universités de France Série latine - coll. Budé; 146), Paris, 224 p.

SAINT-DENIS E. DE (éd., trad.) 1967. — Pline l'Ancien, Histoire naturelle. Livre XXXII, Remèdes tirés des animaux aquatiques. Les Belles Lettres (coll. des Universités de France, Série latine - coll. Budé, 183).
SAinT-Denis E. DE (éd., trad.) 1975. — Ovide, Halieutiques. Les Belles Lettres (coll. des universités de France Série latine - coll. Budé; 217), Paris, $78 \mathrm{p}$.

Stadler H. (éd.) 1920. - Albertus Magnus, De animalibus. Libri XXVI, Nach del Cölner Urschrift. Aschendorff (coll. Beiträge zur Geschichte der Philosophie und Theologie des Mittelalters; 16), Münster, xxvi $+892 \mathrm{p}$.

STANGe E. 1906. - Saxo Arnold, Die Encyklopädie des Arnoldus Saxo, zum ersten Mal nach einem Erfurter Codex. II, De naturis animalium; III, De gemmarum virtutibus; $I V$, De virtute universali. Bartholomäus, Erfurt.

Thompson D. W. 1947. - A Glossary of Greek Fishes. Oxford University Press (St. Andrews University Publications; 45), Oxford, $302 \mathrm{p}$

VAN DEN ABEele B. 2008. - Diffusion et avatars d'une encyclopédie: le Liber de natura rerum de Thomas de Cantimpré, in DE CAllataÿ G. \& VAN DEN AbeEle B. (éds), Une lumière venue d'ailleurs: héritages et ouvertures dans les encyclopédies d'Orient et d'Occident au Moyen Âge. Actes du colloque de Louvain-la-Neuve, 19-21 mai 2005. Brepols (coll. Reminisciences; 9), Turnhout: 141-176. https://doi.org/10.1484/M.REM-EB.3.2746

Van OppenraAij A. M. I. (éd.) 1992. - De Animalibus. Michael Scot's Arabic-Latin Translation. Vol. 3, Books XV-XIX: Generation of Animals. E. J. Brill (coll. Aristoteles Semitico-Latinus; 5/3), Leyde, Boston, Cologne, xxviii + 506 p. https://doi. org/10.1163/9789004451865

Van OppenraAiJ A. M. I. (éd.) 1998. - De Animalibus. Michael Scot's Arabic-Latin Translation. Vol. 2, Books XI-XIV: Parts of Animals. E. J. Brill (coll. Aristoteles Semitico-Latinus; 5/2), Leyde, Boston, Cologne, 592 p. https://doi.org/10.1163/9789004451001

Soumis le 28 août 2020; accepté le 25 novembre 2020 . publié le 10 décembre 2021. 